\title{
Simulated Atmospheric Response to Regional and Pan-Arctic Sea Ice Loss
}

\author{
JAMES A. SCREEN \\ University of Exeter, Exeter, Devon, United Kingdom
}

(Manuscript received 7 March 2016, in final form 6 January 2017)

\begin{abstract}
The loss of Arctic sea ice is already having profound environmental, societal, and ecological impacts locally. A highly uncertain area of scientific research, however, is whether such Arctic change has a tangible effect on weather and climate at lower latitudes. There is emerging evidence that the geographical location of sea ice loss is critically important in determining the large-scale atmospheric circulation response and associated midlatitude impacts. However, such regional dependencies have not been explored in a thorough and systematic manner. To make progress on this issue, this study analyzes ensemble simulations with an atmospheric general circulation model prescribed with sea ice loss separately in nine regions of the Arctic, to elucidate the distinct responses to regional sea ice loss. The results suggest that in some regions, sea ice loss triggers large-scale dynamical responses, whereas in other regions sea ice loss induces only local thermodynamical changes. Sea ice loss in the BarentsKara Seas is unique in driving a weakening of the stratospheric polar vortex, followed in time by a tropospheric circulation response that resembles the North Atlantic Oscillation. For October-March, the largest spatial-scale responses are driven by sea ice loss in the Barents-Kara Seas and the Sea of Okhotsk; however, different regions assume greater importance in other seasons. The atmosphere responds very differently to regional sea ice losses than to pan-Arctic sea ice loss, and the response to pan-Arctic sea ice loss cannot be obtained by the linear addition of the responses to regional sea ice losses. The results imply that diversity in past studies of the simulated response to Arctic sea ice loss can be partly explained by the different spatial patterns of sea ice loss imposed.
\end{abstract}

\section{Introduction}

Satellites have routinely measured Arctic sea ice since the late 1970s. Since then, the sea ice cover has significantly reduced in all calendar months, with the largest trend in September - the month of the annual minimum (Simmonds 2015). The September sea ice extent has declined by $40 \%$ and its volume by an estimated $65 \%$ (IPCC 2013). Paleoclimate records suggest the sea ice cover is now lower than at any time in the previous $1450 \mathrm{yr}$ (Kinnard et al. 2011). This decline in Arctic sea ice cover is already having profound societal and ecological impacts locally (e.g., Bhatt et al. 2014; Post et al. 2013). An emerging and highly uncertain area of scientific research, however, is whether such Arctic change has a tangible effect on weather and climate at lower latitudes. A recent spate of extreme weather events in the midlatitudes, occurring at a time of record low sea ice, has prompted debate about possible linkages between Arctic sea ice loss and midlatitude weather (e.g., Cohen et al. 2014; Vihma 2014; Walsh 2014; Overland

Corresponding author e-mail: Dr. James Screen, j.screen@ exeter.ac.uk et al. 2015; Barnes and Screen 2015). A number of recent papers have argued for a causal link, based on detailed analyses of atmospheric observations. However, in such a strongly coupled system, diagnosing cause and effect is a nearly intractable problem with observations alone. For this reason, recent work has turned to a "modeling attribution" approach and multiple modeling studies have implicated reduced Arctic sea ice cover as an important driver of Arctic and/or lower-latitude climate (Deser et al. 2010, 2015, 2016; Screen et al. 2013, 2014, 2015a,b; Peings and Magnusdottir 2014; Sun et al. 2015; Blackport and Kushner 2016; Cvijanovic and Caldeira 2015; Ayarzagüena and Screen 2016; and many others). While such model experiments have undoubtedly improved our understanding of the atmospheric response to Arctic sea ice loss, existing work has largely focused on the impacts of pan-Arctic sea ice loss (with some exceptions noted later). Yet, the geographical regions of sea ice anomalies vary from year to year, and the spatial pattern of future sea ice loss is highly uncertain. Thus, for both seasonal prediction and climate projections, it is important to better understand the atmospheric response to regional sea ice anomalies. Furthermore, in the literature there exists a wide diversity 
of model responses to Arctic sea ice loss. It is unclear the extent to which these discrepancies arise due to differences in a model's forced response or differences in the sea ice forcing. Concerning the latter, different studies have imposed different spatial patterns of sea ice loss, which may in part explain the diversity of model responses identified.

Given the complexity of the climate system, sea ice anomalies in one geographical location would not be expected to lead to the same atmospheric response as sea ice anomalies in another region. Indeed, there is emerging evidence that the location of sea ice loss is critically important in determining the large-scale circulation response and associated midlatitude impacts. In atmospheric general circulation model (AGCM) experiments, Sun et al. (2015) found opposing responses of the zonal-mean westerlies in response to projected future sea ice loss in the Atlantic and Pacific sectors. Specifically, sea ice loss in the Atlantic sector caused a weakening of the upper-level westerly winds, whereas sea ice loss in the Pacific sector caused a strengthening. Pedersen et al. (2016) also found contrasting wintertime atmospheric circulation responses to sea ice loss in the Atlantic and Pacific sectors, and highlighted differing effects on the North Atlantic Oscillation (NAO). Sea ice loss in the Atlantic and Pacific sectors of the Arctic caused westward and eastward shifts of the Icelandic low, respectively. One implication of these results is that the relative rates of future sea ice loss in the Atlantic and Pacific sectors, which are poorly constrained in models, may be important for determining the character of the atmospheric response. More precisely, the spatial pattern of projected sea ice loss is highly uncertain and not just the relative rates of Atlantic and Pacific sector ice loss. This motivates a more detailed analysis of the sensitivity of the atmospheric response to the geographical location of sea ice loss, going beyond the Atlantic/Pacific classification, to consider the responses to sea ice loss in nine specific regions.

Certain "hot spot" regions have been proposed where sea ice loss is more effective at influencing the largescale atmospheric circulation. For example, it has been suggested that sea ice anomalies in the Barents-Kara Seas (Honda et al. 2009; Petoukhov and Semenov 2010; Mori et al. 2014), North Atlantic (Magnusdottir et al. 2004; Deser et al. 2004), and the Sea of Okhotsk (Honda et al. 1996) can trigger large-scale atmospheric circulation anomalies with consequent effects on temperature and precipitation over midlatitudes. While such studies have simulated the response to sea ice anomalies in a specific region, it is difficult to make direct comparisons between disparate studies that have utilized different models and experimental designs. To make progress on this issue, this study presents results from experiments with a single model, with sea ice altered separately in all Arctic subregions in a systematic and consistent manner, to elucidate the distinct responses to regional sea ice loss.

Regional sea ice anomalies may provide seasonal prediction skill of winter climate over the extratropical Northern Hemisphere. Based on the correlation between sea ice variation in eight different Arctic regions and atmospheric reanalysis data, Koenigk et al. (2016) suggested that sea ice variations in the Barents Sea are most important for the sign of the winter NAO, but the amplitude was also influenced by sea ice variations in the Greenland and Labrador Seas. Central and western European winter temperatures were most strongly correlated with ice variability in the Greenland Sea. Ice variations in the Laptev-East Siberian Seas appeared to have the largest impact of blocking frequency in the Euro-Atlantic region. Scaife et al. (2014) attributed some of the predictive skill of the winter NAO in the Met Office seasonal forecasting system to initialization of November sea ice anomalies in the Kara Sea. Rinke et al. (2013) used a compositing approach to contrast years of low and high sea ice in different regions of the Arctic Ocean based on hindcasts with a high-resolution coupled atmosphere-ocean regional model. These authors concluded that sea ice anomalies in the BarentsKara Seas and the Beaufort Sea influence the wintertime atmospheric circulation more strongly than those in the Laptev or East Siberian-Chukchi Seas. However, a weakness of their compositing approach is that confounding influences of simultaneous sea ice and sea surface temperature (SST) anomalies from other regions cannot be ruled out. Improved knowledge of the distinct responses to regional sea ice anomalies could therefore improve seasonal prediction.

\section{Data and methods}

\section{a. Model simulations}

Simulations were performed with the Met Office Unified Model (version 6.6.3), which constitutes the atmospheric component of the HadGEM2 (Martin et al. 2011) coupled climate model used in phase 5 of the Coupled Model Intercomparison Project (CMIP5). This model configuration has a horizontal resolution of $1.857^{\circ}$ longitude $\times 1.25^{\circ}$ latitude and 38 vertical levels. Eleven equilibrium experiments were performed: a control, nine perturbation experiments with regional sea ice anomalies, and a perturbation experiment with panArctic sea ice anomalies (i.e., the sum of all regional experiments). A fixed, annually repeating seasonal cycle of sea ice concentration (SIC) and SST was prescribed in 
a) March SIC

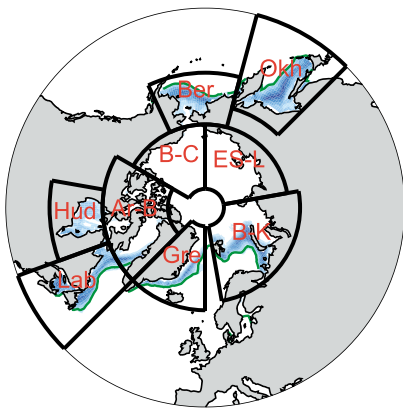

e) March SST
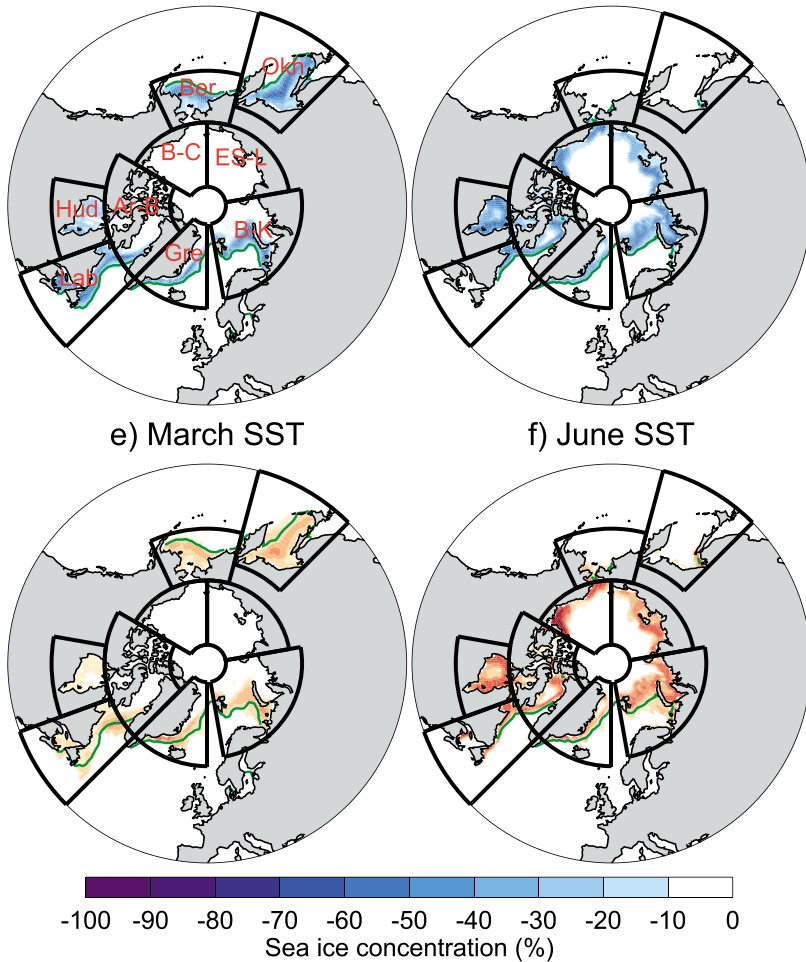

f) June SST c) September SIC

FIG. 1. SIC anomalies (relative to the control run) in each of the regional perturbation experiments for (a) March, (b) June, (c) September, and (d) December. The green lines correspond to the $15 \%$ contour in the control experiment, and the black boxes show the regional domains. (e)-(h) As (a)-(d), but for SST.

each case. In the control experiment, the prescribed ocean surface boundary conditions were based on the annual cycle of climatological monthly mean (1979-2013) SIC and SST, taken from HadISST (Rayner et al. 2003). In each of the perturbation experiments, an anomaly of monthly SIC of two standard deviations (calculated over the period 1979-2013) was subtracted from the climatological (control) SIC value at each ice-covered grid box within a chosen regional domain. To allow for SST warming when SIC is reduced, an anomaly in monthly SST of two standard deviations was added to the climatological (control) SST value at all partially ice-covered grid boxes within the chosen regional domain. The monthly SST of non-ice-covered grid boxes within the regional domain was unaltered from the control experiment. The SIC and SST outside the chosen regional domain were also unaltered from the control experiment. A smoothing of $10^{\circ}$ longitude and $5^{\circ}$ latitude was applied to the anomaly fields prior to their addition to, or subtraction from, climatological values. The only effect of this smoothing is to lessen the (unrealistic) SIC and SST gradients at the edges of the regional domains. To avoid unphysical values, SIC is constrained to be between $0 \%$ and $100 \%$ and SST to not fall below the freezing point

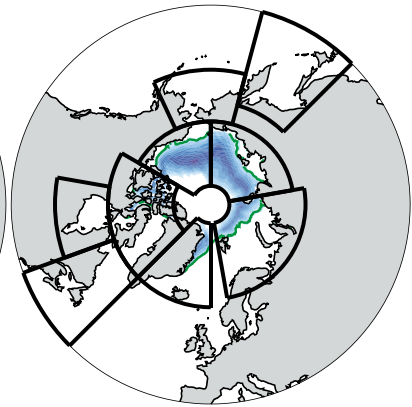

g) September SST

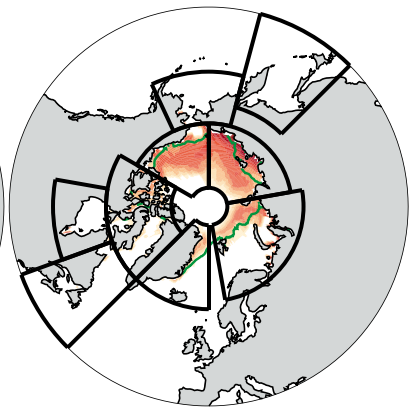

h) December SST
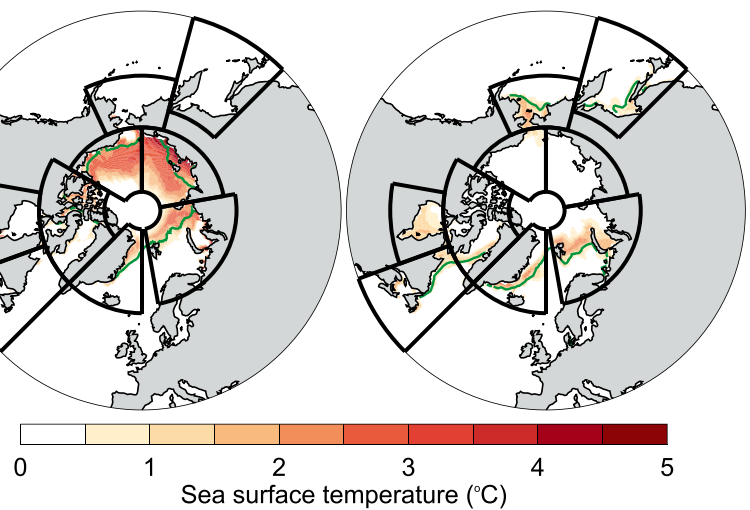

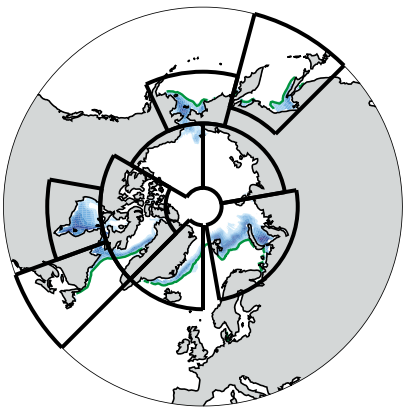

d) December SIC 
TABLE 1. Covariance between observed monthly mean SIC averaged over the nine regional domains, expressed as a percentage of shared variance ( $r^{2}$ multiplied by 100 , rounded to the nearest integer). All time series were linearly detrended first.

\begin{tabular}{lccccccrrr}
\hline \hline & B-K & ES-L & B-C & Ar-B & Gre & Okh & Ber & Hud & Lab \\
\hline B-K & - & 2 & 2 & 0 & 10 & 0 & 4 & 1 \\
ES-L & 2 & - & 20 & 10 & 2 & 0 & 0 & 0 \\
B-C & 2 & 20 & - & 3 & 1 & 0 & 1 & 0 \\
Ar-B & 0 & 10 & 3 & - & 1 & 2 & 1 & 0 \\
Gre & 10 & 2 & 1 & 1 & - & 8 & 0 & 1 \\
Okh & 0 & 0 & 0 & 2 & 8 & - & 10 & 0 \\
Ber & 4 & 0 & 1 & 1 & 0 & 10 & - & 1 \\
Hud & 1 & 0 & 0 & 9 & 1 & 0 & 1 & 4 \\
Lab & 1 & 0 & 0 & 5 & 5 & 19 & 4 & 4 \\
\hline
\end{tabular}

follows: Barents-Kara Seas (B-K; $65^{\circ}-85^{\circ} \mathrm{N}, 10^{\circ}-$ $100^{\circ} \mathrm{E}$ ), East Siberian-Laptev Seas (ES-L; $68^{\circ}-85^{\circ} \mathrm{N}$, $100^{\circ}-180^{\circ} \mathrm{E}$ ), Beaufort-Chukchi Seas (B-C; $68^{\circ}-85^{\circ} \mathrm{N}$, $180^{\circ}-240^{\circ} \mathrm{E}$ ), Canadian Archipelago-Baffin Bay (Ar-B; $\left.63^{\circ}-80^{\circ} \mathrm{N}, 240^{\circ}-315^{\circ} \mathrm{E}\right)$, Greenland Sea $\left(\mathrm{Gre} ; 63^{\circ}-85^{\circ} \mathrm{N}\right.$, $\left.315^{\circ}-360^{\circ} \mathrm{E}\right)$, Sea of Okhotsk (Okh; $40^{\circ}-63^{\circ} \mathrm{N}, 135^{\circ}-$ $\left.165^{\circ} \mathrm{E}\right)$, Bering Sea (Ber; $\left.55^{\circ}-68^{\circ} \mathrm{N}, 165^{\circ}-205^{\circ} \mathrm{E}\right)$, Hudson Bay (Hud; $50^{\circ}-63^{\circ} \mathrm{N}, 260^{\circ}-290^{\circ} \mathrm{E}$ ), and Labrador Sea $\left(\mathrm{Lab} ; 40^{\circ}-63^{\circ} \mathrm{N}, 290^{\circ}-315^{\circ} \mathrm{E}\right)$. Sea ice variability in these regions is largely independent from one another (Table $1)$. The highest covariances are found between the Beaufort-Chukchi Seas and East Siberian-Laptev Seas, and between the Sea of Okhotsk and Labrador Sea regions; however, in both cases the shared variance is no more than $20 \%$, implying a large degree of regional independence.

\section{Results}

\section{a. Sea ice and surface heat fluxes}

The prescribed regional sea ice anomalies are shown in Fig. 1. The spatial patterns of the anomalies are constrained by design and limited to the chosen region. With in each region, the largest anomalies are found at the ice edge, reflecting the larger variability of sea ice cover along the ice edge compared to within the ice pack. The temporal pattern of the anomalies reflects the seasonal cycle of the mean sea ice cover and its variability. For example, over the East SiberianLaptev Seas and the Beaufort-Chukchi Seas, the largest anomalies are in summer, whereas over the Sea of Okhotsk and the Bering Sea the anomalies are largest in winter.

Figure 2a shows the seasonal cycle of sea ice area loss in each regional experiment, more clearly showing that the seasonal timing of sea ice loss differs between the experiments. Ice loss in the Beaufort-Chukchi Seas and the East Siberian-Laptev Seas is largest in AugustOctober and weakest in December-April. Over the
Barents-Kara Seas, the Canadian Archipelago-Baffin Bay, and Hudson Bay, sea ice loss maximizes in June and in November-December with minima in September and March. Sea ice loss over the Sea of Okhotsk, the

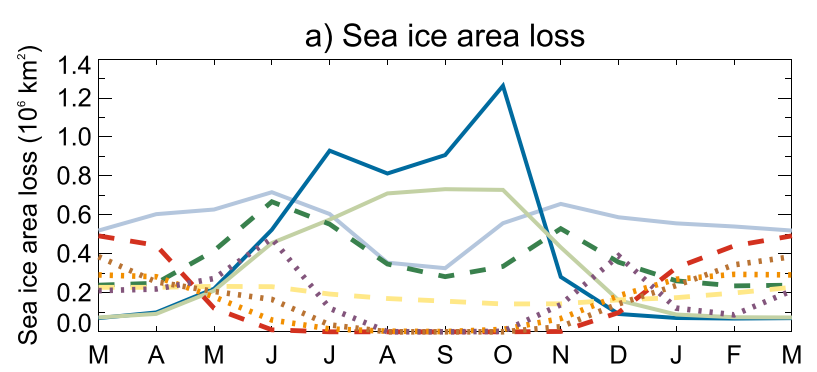

b) Area-average heat flux to atmosphere

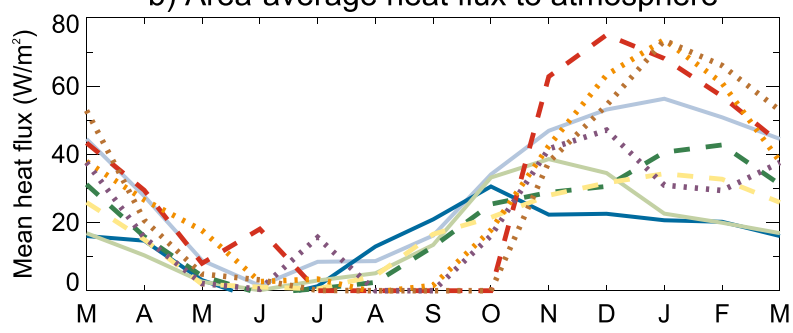

C) Total forcing to atmosphere

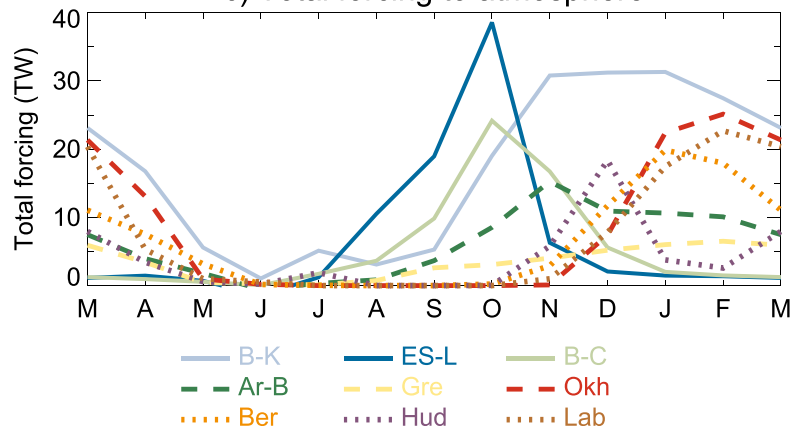

FIG. 2. (a) Annual cycle of sea ice area (defined as the area of each grid cell multiplied by its SIC, summed over the Northern Hemisphere) anomalies in each regional experiment, relative to the control run. (b) Annual cycle of the net surface heat flux response, averaged over the ice loss regions. (c) Annual cycle of total forcing, summed over the ice loss regions [i.e., values in (a) multiplied by values in (b)]. 
Bering Sea, and the Labrador Sea is largest in JanuaryApril and smallest (zero) in July-October, when these regions are seasonally ice free. Sea ice loss in the Greenland Sea is relatively small with only a weak seasonal cycle. The loss of sea ice cover results in modified ocean-to-atmosphere heat fluxes, the magnitude of which at any point depends, among other things, on the air-sea temperature difference and the timing of sea ice refreeze. The air-sea temperature difference is largest in winter and sea ice growth is largest in autumn and as a result, the area-averaged flux response over regions of sea ice loss is largest in these seasons (Fig. 2b), irrespective of the seasonal cycle of sea ice loss.

The net forcing on the atmosphere arising from sea ice loss (Fig. 2c) depends on both the areal extent of sea ice loss (Fig. 2a) and the area-averaged heat flux (Fig. 2b). For lower-latitude regions (the Sea of Okhotsk, the Bering Sea, the Labrador Sea), the annual cycles of sea ice loss and the area-mean heat flux are roughly in phase, so the annual cycle of forcing also matches that of sea ice area loss (i.e., there is no time lag between the peak sea ice loss and the peak forcing to the atmosphere). Over the high-latitude regions, however, this is not the case. Over the East Siberian-Laptev Seas and the BeaufortChukchi Seas, the forcing on the atmosphere occurs predominately in the autumn months, despite sea ice area losses throughout the summer months. Over the Barents-Kara Seas, the Canadian Archipelago-Baffin Bay, and the Hudson Bay, the early summer peak in sea ice loss is not seen in the forcing to the atmosphere, which is largest in autumn and winter. Thus, the atmospheric response lags the loss of sea ice, as reported in previous studies (Screen et al. 2013; Deser et al. 2010, 2015). The remainder of this manuscript focuses on the Northern Hemisphere extratropical atmospheric response averaged over October-March, chosen to capture the month(s) of maximum net forcing in all regional experiments.

\section{b. Temperature and precipitation}

The October-March near-surface air temperature (TAS) response is shown in Fig. 3. Consistent with enhanced energy transfer from the ocean to the atmosphere, the lower atmosphere warms in the regions of sea ice loss, and this warming spreads to neighboring regions. The TAS responses are locally strong in regions of sea ice loss, but they are generally weak and with patchy statistical significance farther afield. The significant warming responses are largely confined to regions of sea ice loss in all experiments. A significant cooling is simulated over large parts of Eurasia in response to sea ice loss in the Canadian
Archipelago-Baffin Bay region (Fig. 3d) and the Sea of Okhotsk (Fig. 3f). A band of cooling across the northern United States and southern Canada is found in response to sea ice loss in the East Siberian-Laptev Seas (Fig. 3b). Cooling is also simulated over North America in response to sea ice loss in the Barents-Kara Seas (Fig. 3a), the Canadian Archipelago-Baffin Bay (Fig. 3d), the Greenland Sea (Fig. 3e) and the Bering Sea (Fig. 3g), but it is only significant over a large area in response to sea ice loss in the Greenland Sea. Although the remote TAS responses are generally weak (and insignificant), it is noteworthy that they predominantly indicate cooling rather than warming. This result is in contrast to the general warming tendency simulated in response to Arctic-wide sea ice losses (see, e.g., Screen et al. 2015a,b), a point we will return to in the discussion section.

Do these October-March mean cooling tendencies translate into altered cold extremes? Figure 4 shows simulated changes in the frequency, intensity, and duration of winter (December-February) cold-air outbreaks (CAOs) over Northern Hemisphere extratropical land regions (shown in Fig. 4a), defined as in Ayarzagüena and Screen (2016). The frequency of CAOs is not significantly altered in any of the domains considered in response to sea ice loss in any region (Fig. 4b). Significant changes in CAO intensity are simulated in some regions and experiments, but there is no overall consistency in the sign of these changes (Fig. 4c). The strongest increases in CAO intensity (i.e., cooler) are found over Scandinavia (SCA) in response to sea ice loss over the East Siberian-Laptev Seas, the Canadian Archipelago-Baffin Bay, and the Greenland Sea. The strongest decreases in CAO intensity are found over the eastern United States (EUS) in response to sea ice loss in the Beaufort-Chukchi Seas and Hudson Bay; over the central United States (CUS) in response to sea ice loss in the Sea of Okhotsk; over Alaska and western Canada (AWC) in response to sea ice loss in the Canadian Archipelago-Baffin Bay; and over eastern Canada and Greenland (ECG) in response to sea ice loss in the Greenland Sea. CAO duration is decreased over the western United States (WUS) in response to sea ice loss in the East Siberian-Laptev Seas, the Canadian Archipelago-Baffin Bay, and the Bering Sea (Fig. 4d). Shorter CAOs are also simulated over central Europe (CEU), central Asia (CAS), and eastern Canada and Greenland (ECG) in response to sea ice loss in the East Siberian-Laptev Seas, the Canadian Archipelago-Baffin Bay, and the Greenland Sea, respectively. In short, despite an overall tendency for cooler October-March mean temperatures over northern continents in many of the experiments, there is 
a) Barents-Kara Sea

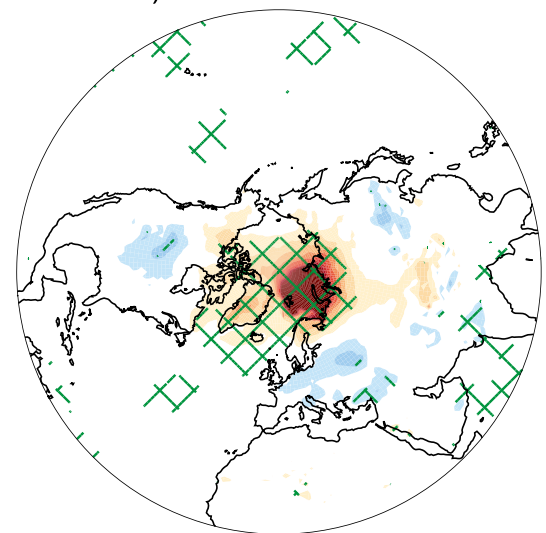

d) Archipelago-Baffin Bay

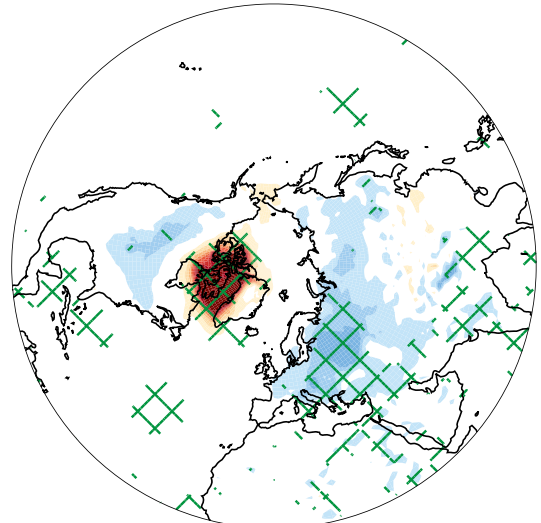

g) Bering Sea

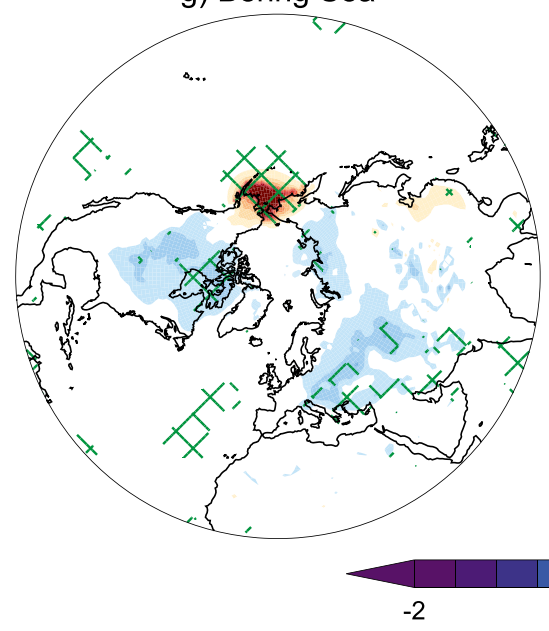

b) East Siberian-Laptev Sea

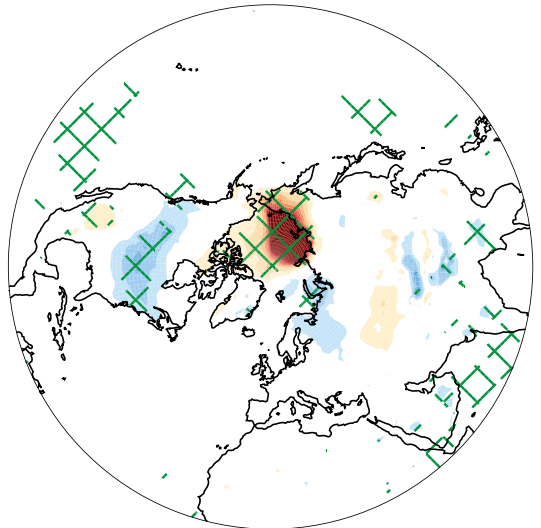

e) Greenland Sea

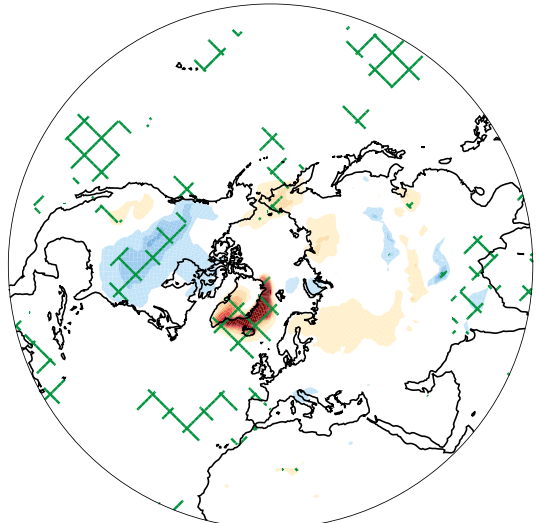

h) Hudson Bay

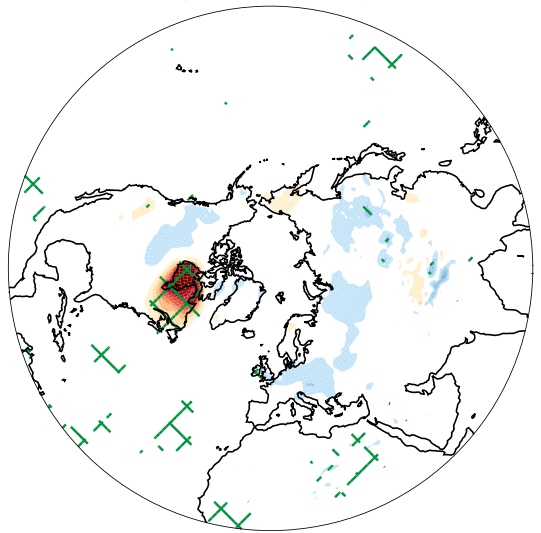

c) Beaufort-Chukchi Sea

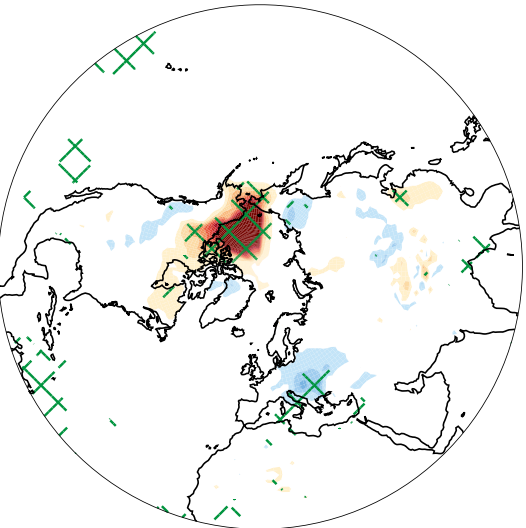

f) Sea of Okhotsk

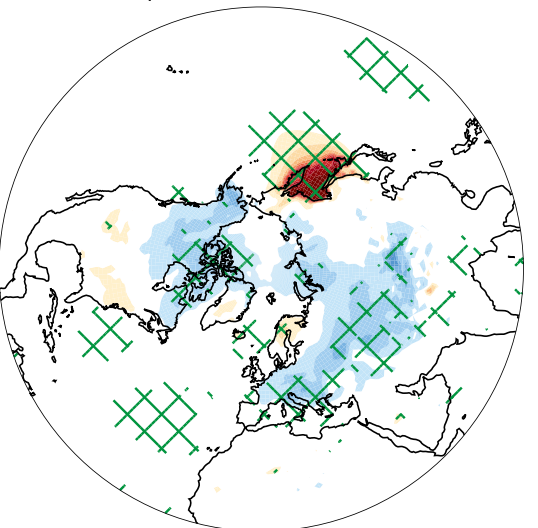

i) Labrador Sea

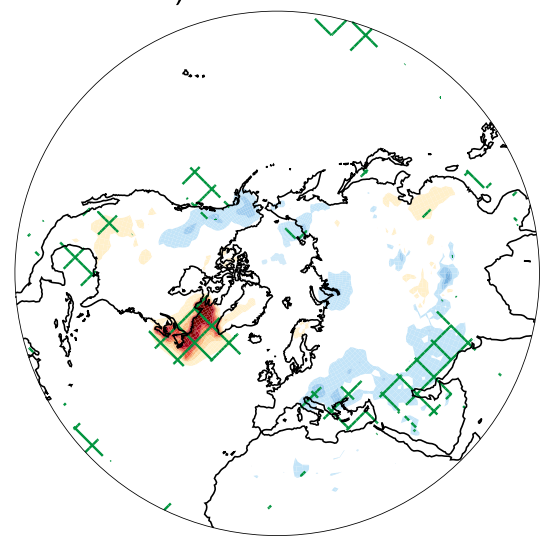

FIG. 3. October-March mean 1.5-m air temperature responses to sea ice loss in the (a) Barents-Kara Seas, (b) East Siberian-Laptev Seas, (c) Beaufort-Chukchi Seas, (d) Canadian Archipelago-Baffin Bay, (e) Greenland Sea, (f) Sea of Okhotsk, (g) Bering Sea, (h) Hudson Bay, and (i) Labrador Sea. Green hatching denotes a statistically significant response at the $95 \%$ confidence level.

no general increase in the frequency, intensity, or duration of CAOs.

Precipitation increases in the vicinity of regions of sea ice loss (Fig. 5), linked to increased moisture availability and warming (moisture-holding capacity). Away from these regions, the precipitation responses are weak, of variable sign, and largely insignificant. The most coherent feature of the remote precipitation responses is a 
a)
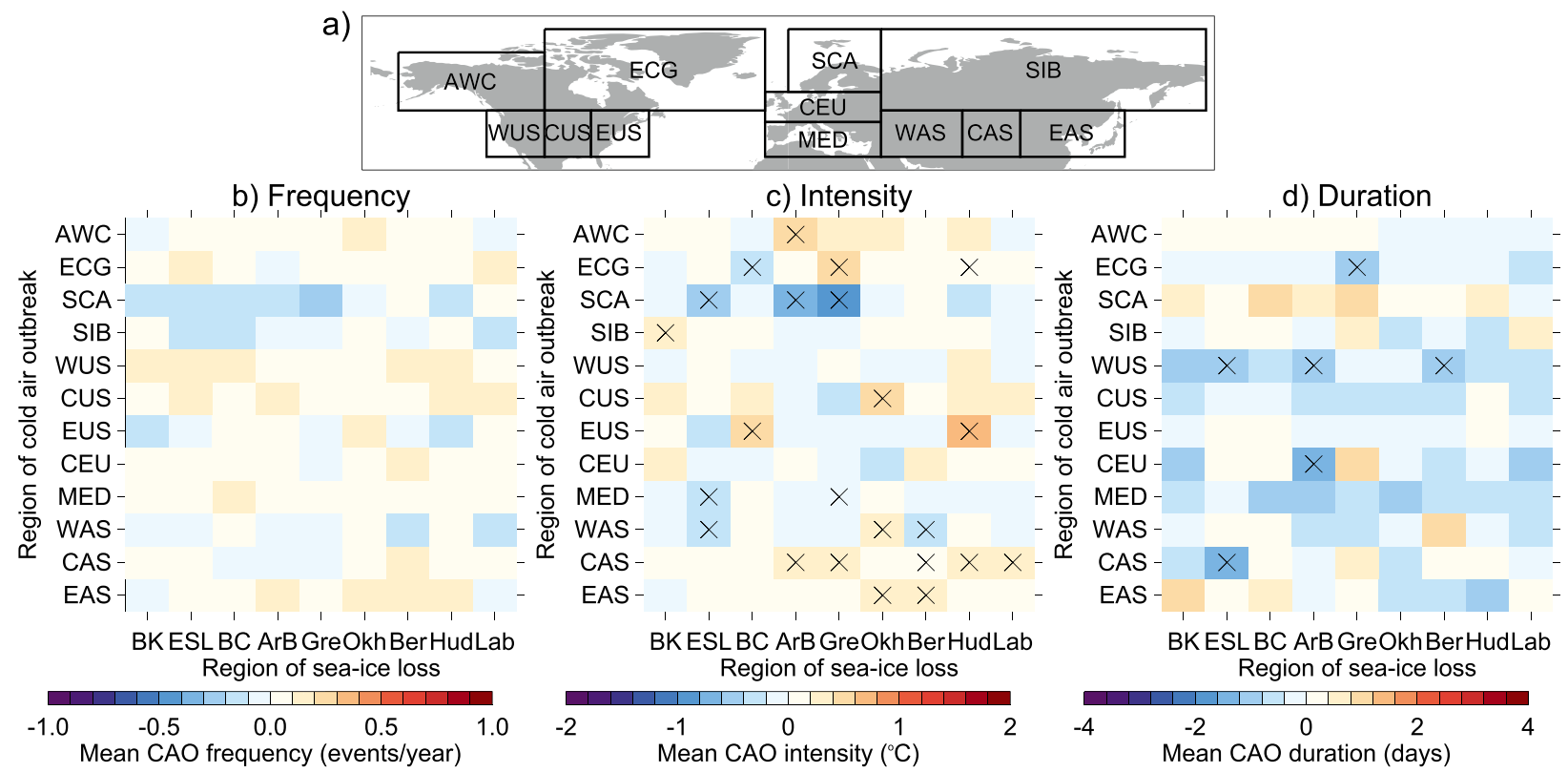

FIG. 4. (a) Regions used in the calculation of CAO statistics. Simulated responses of CAO (b) frequency, (c) intensity and (d) duration. Black $\times$ symbols denote statistically significant responses at the $95 \%$ confidence level.

drying over northwest Europe in response to sea ice loss in the Barents-Kara Seas (Fig. 5a).

\section{c. Atmospheric circulation}

The midtropospheric $(500 \mathrm{hPa})$ geopotential height (Z500) response is shown in Fig. 6. Sea ice loss in the Barents-Kara Seas causes an increase in Z500 over the northern North Atlantic and a decrease in Z500 from the mid-Atlantic to eastern Europe at roughly $40^{\circ} \mathrm{N}$ (Fig. 6a). This response pattern projects strongly onto the negative phase of the NAO. Indeed, indices of the NAO and its hemispheric counterpart the northern annular mode (NAM) display a significant reduction in response to sea ice loss in the Barents-Kara Seas (Table 2). Sea ice loss in the other regions does not have a significant impact on the NAO or NAM indices. Sea ice loss in the East Siberian-Laptev Seas induces a localized increase in Z500 but no significant large-scale response (Fig. 6b). Sea ice loss in the Beaufort-Chukchi Seas invokes a height anomaly dipole over the North Atlantic, with elevated Z500 west of the United Kingdom and decreased Z500 over the Mediterranean and west of Morocco (Fig. 6c). This response pattern is shifted southward compared to the classical NAO pattern and hence does not project strongly onto the NAO. The loss of sea ice in the Canadian Archipelago-Baffin Bay causes elevated Z500 downstream to the north of the United Kingdom (Fig. 6d). Sea ice loss in the Greenland Sea induces a height anomaly dipole in the North Atlantic similar to that in response to sea ice loss in the Beaufort-Chukchi Seas, and also a dipole over the North Pacific (Fig. 6e). Sea ice loss in the Sea of Okhotsk triggers an anomalous wave train across the North Pacific and North America, and also elevated Z500 over Scandinavia and reduced Z500 over Asia (Fig. 6f). A weaker and slightly eastward-shifted pattern to that just described is simulated in response to sea ice loss in the Bering Sea (Fig. 6g). The response to sea ice loss in the Hudson Bay is largely insignificant (Fig. 6h). Sea ice loss in the Labrador Sea leads to reduced Z500 over the northwest and elevated Z500 over the southeast of North America (Fig. 6i).

Figure 7 shows the 700-hPa zonal wind (U700) response. The U700 weakens over northern Europe and strengthens over northern Africa in response to sea ice loss in the Barents-Kara Seas, indicating a southward shift of the latitude of maximum westerly winds (Fig. 7a). A southward shift of the westerlies over the United States is simulated in response to sea ice loss in the East Siberian-Laptev Seas (Fig. 7b) and likely contributes to the collocated cooling response in this experiment. A tripole pattern over the North Atlantic and Europe-with weakened U700 at the latitude of the climatological maximum westerlies and strengthened U700 to the north and south-is simulated in response to sea ice loss in the Beaufort-Chukchi Seas (Fig. 7c) and Greenland Sea (Fig. 7e). Ice loss in the Sea of Okhotsk and the Greenland Sea induces a weaker and southwardexpanded westerly wind belt across the Pacific (Figs. 7e,f). Sea ice loss in the Sea of Okhotsk also causes northwardshifted winds over the Atlantic (Fig. 7f). No notable U700 
a) Barents-Kara Sea

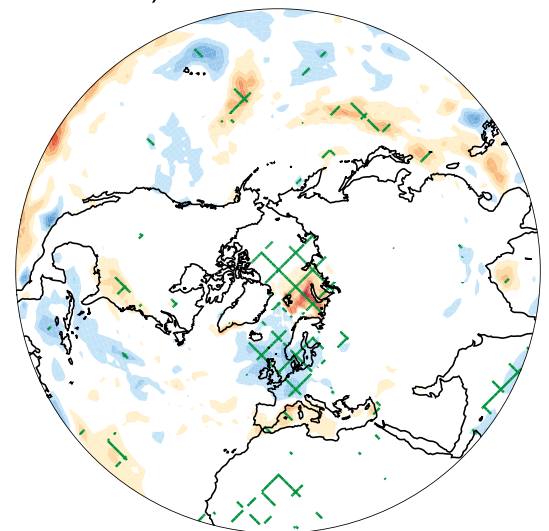

d) Archipelago-Baffin Bay

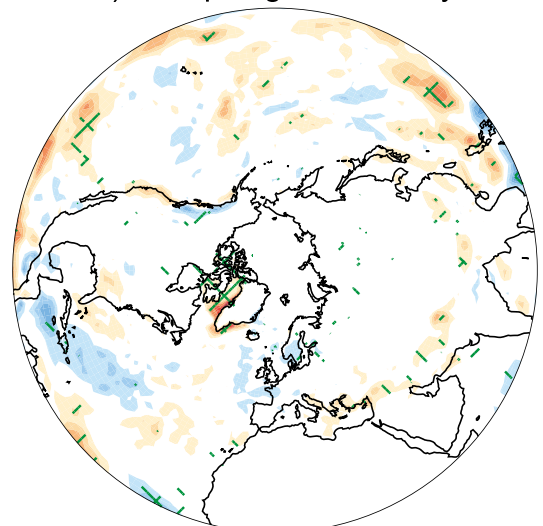

g) Bering Sea

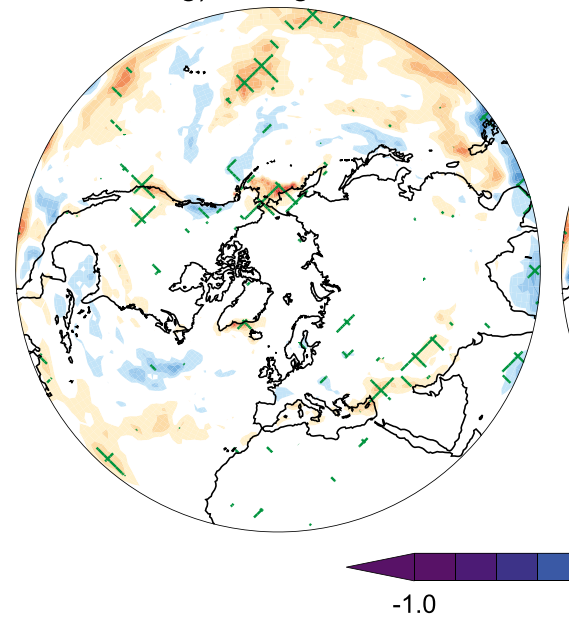

b) East Siberian-Laptev Sea

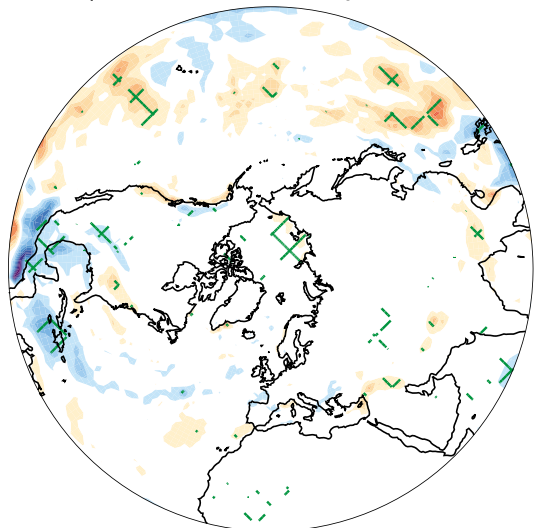

e) Greenland Sea

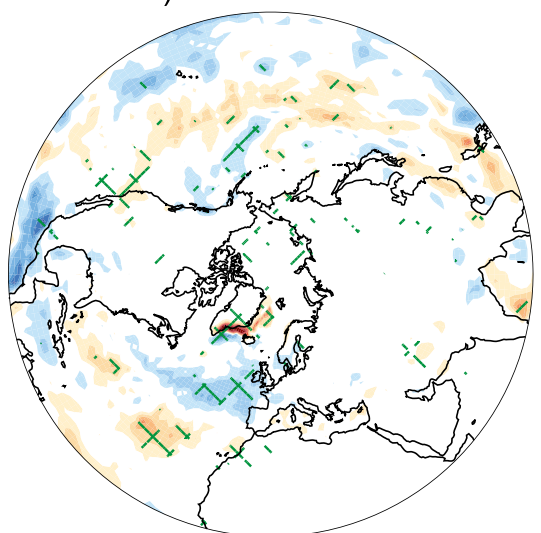

h) Hudson Bay

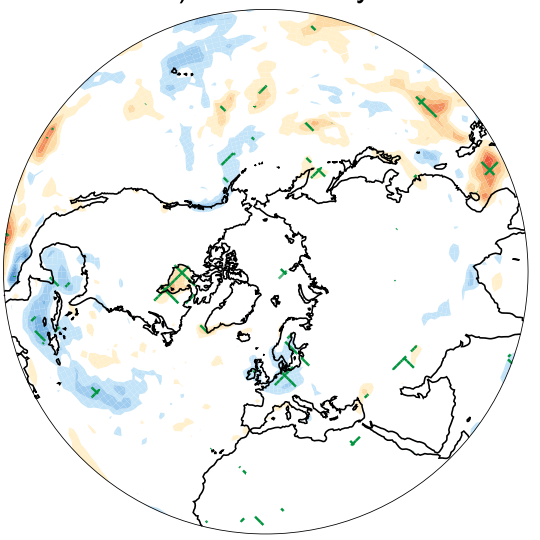

$-0.5$

Precipitation ( $\mathrm{mm} / \mathrm{day})$

0.5

1.0

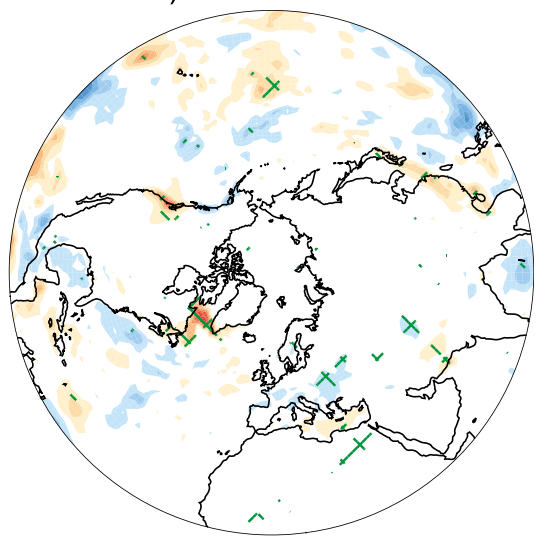

c) Beaufort-Chukchi Sea

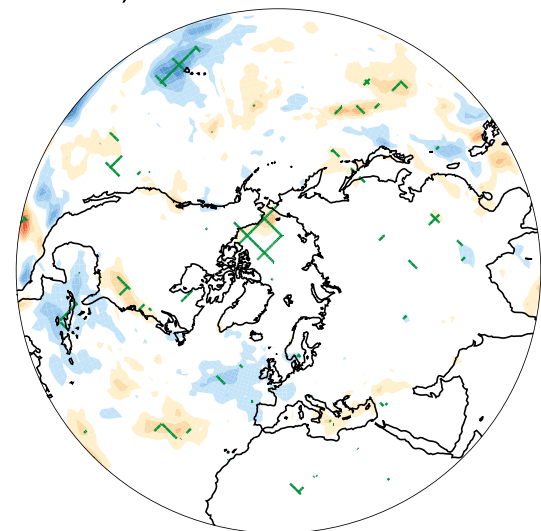

f) Sea of Okhotsk

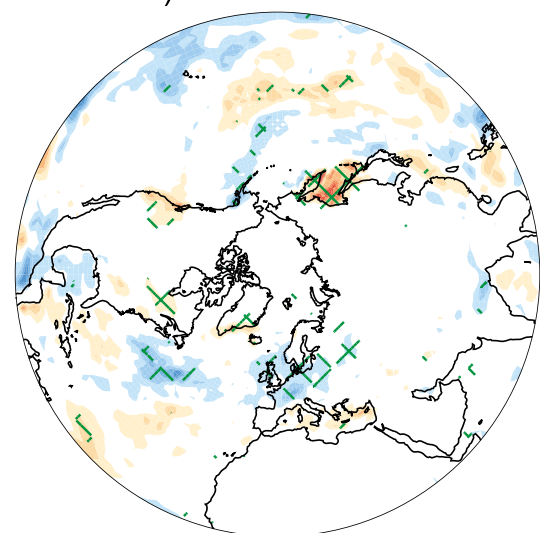

i) Labrador Sea

FIG. 5. As in Fig. 3, but for the precipitation response to sea ice loss.

changes are found in response to sea ice loss in the Canadian Archipelago-Baffin Bay, the Bering Sea, the Hudson Bay, or the Labrador Sea.

The 300-hPa zonal wind (U300) response is shown in Fig. 8 and an intriguing feature is the broad consistency in the structure of the response over the North Atlantic and
Europe resulting from sea ice loss in many disparate regions. A decrease in U300 at the latitude of the United Kingdom and an increase in U300 at the latitude of northern Africa is a common response to sea ice loss in all the regions considered, with the possible exception of the Labrador Sea. This dipole response is especially strong in 
a) Barents-Kara Sea

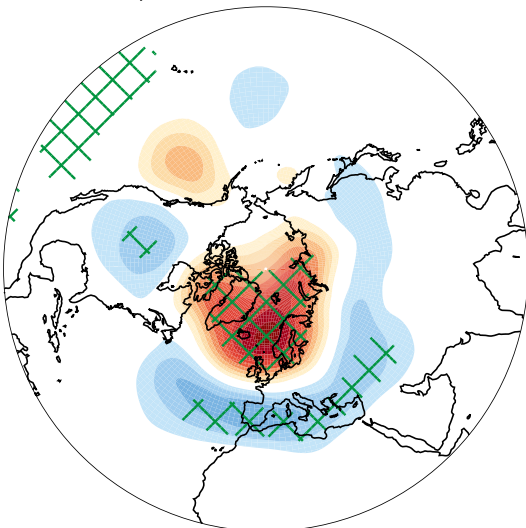

d) Archipelago-Baffin Bay

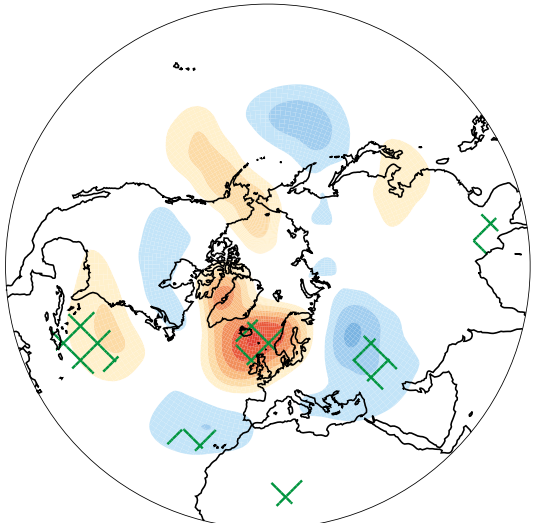

g) Bering Sea

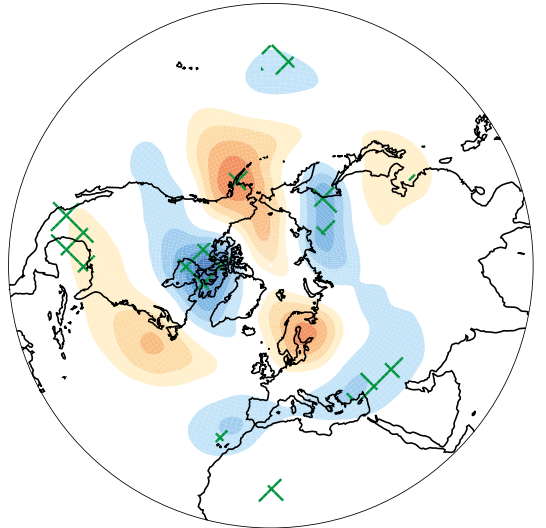

b) East Siberian-Laptev Sea

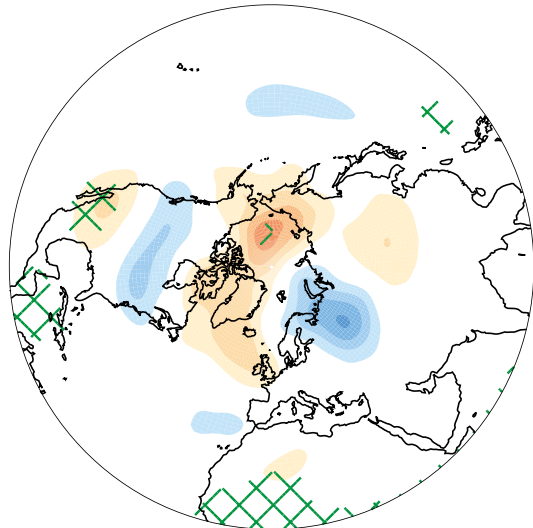

e) Greenland Sea

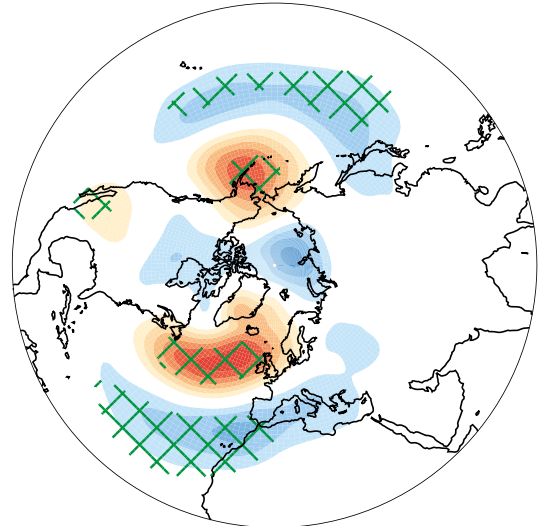

h) Hudson Bay
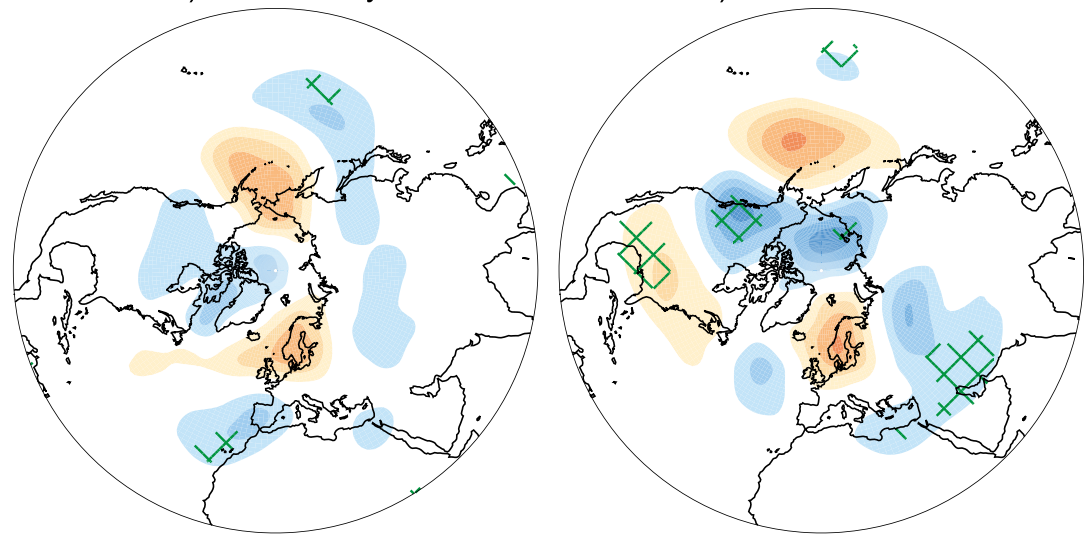

20 c) Beaufort-Chukchi Sea

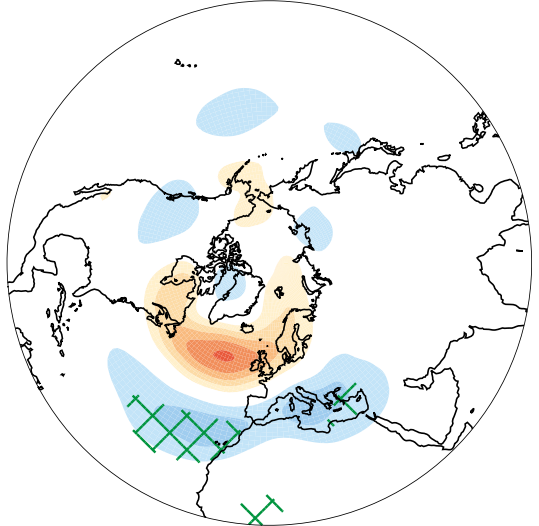

f) Sea of Okhotsk

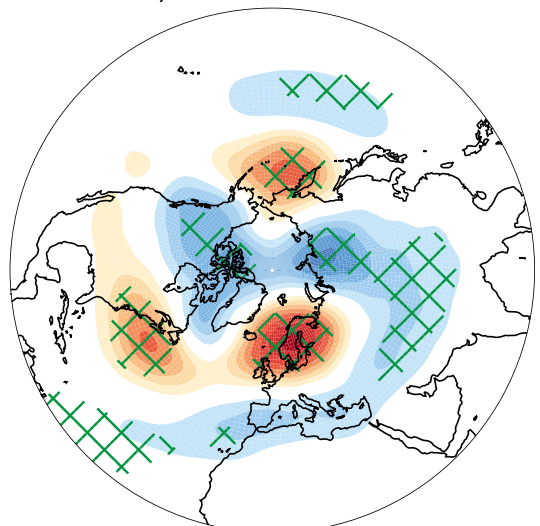

i) Labrador Sea

$-20$

$-10 \underset{500 \mathrm{hPa} \text { geopotential height }(\mathrm{m})}{10}$

FIG. 6. As in Fig. 3, but for the Z500 response.

response to the loss of sea ice in the Barents-Kara Seas (Fig. 8a), the Beaufort-Chukchi Seas (Fig. 8c), the Greenland Sea (Fig. 8e), and the Sea of Okhotsk (Fig. 8f). Over North America the responses are more varied, but in general they depict a weakening of U300 on the equatorward side of the climatological jet and a strengthening on the poleward flank or in the jet core. The strongest responses over North America occur in response to sea ice over the Sea of Okhotsk (Fig. 8f) and the Bering Sea (Fig. 8g). Sea ice losses in the Greenland Sea and four lower-latitude regions all favor an equatorward shift (strengthening on the 
TABLE 2. Change in the October-March mean NAO and NAM indices, defined here as the Z500 averaged over latitudes $30^{\circ}-50^{\circ} \mathrm{N}$ minus that averaged over latitudes $60^{\circ}-80^{\circ} \mathrm{N}$, for the zonal-mean (NAM) or averaged over the Atlantic $\left(0^{\circ}-60^{\circ} \mathrm{W}\right)$ sector $(\mathrm{NAO})$. Changes significant at a $95 \%$ confidence level are shown in italics.

\begin{tabular}{|c|c|c|c|c|c|c|c|c|c|}
\hline & B-K & ES-L & B-C & Ar-B & Gre & Okh & Ber & Hud & $\mathrm{Lab}$ \\
\hline NAO & -14.8 & -4.8 & 0.6 & -6.0 & 0.0 & 3.7 & 3.9 & 1.9 & -0.5 \\
\hline NAM & -8.4 & -2.1 & -1.6 & -3.0 & -0.2 & 1.5 & 0.8 & -1.0 & 2.1 \\
\hline
\end{tabular}

equatorward flank; weakening on the poleward flank) of the climatological jet over the North Pacific (Figs. 8e-i). The U300 responses over Asia are generally weak and inconsistent between experiments. Contrasting the U700 (Fig. 7) and U300 (Fig. 8) responses, it can be seen that their spatial patterns are broadly similar, but the U300 responses are larger in magnitude.

\section{d. Tropospheric and stratospheric pathways}

Tropospheric circulation responses to sea ice loss may be purely governed by tropospheric processes or involve a stratospheric pathway (Sun et al. 2015; Nakamura et al. 2016). One common measure of troposphere-stratosphere interaction is the time evolution of polar cap-averaged geopotential height (e.g., Peings and Magnusdottir 2014; Kim et al. 2014; Sun et al. 2015). Figure 9 shows the polar cap height (PCH) response in the months September-April in each of the regional experiments. The Barents-Kara Seas are the only location where sea ice loss induces a significant stratospheric $\mathrm{PCH}$ response (Fig. 9a), with PCH increased in February and March above $100 \mathrm{hPa}$. In these months $\mathrm{PCH}$ is also increased throughout the troposphere, reaching statistical significance below $700 \mathrm{hPa}$. In the preceding months, there is evidence of downward propagation of the positive $\mathrm{PCH}$ response that emerges in the stratosphere in the autumn months and precedes the latewinter tropospheric response. This familiar response pattern to sea ice loss in the Barents-Kara Seas (Kim et al. 2014) strongly suggests a warming and weakening of the stratospheric vortex, followed by a negative NAO/NAM response with a lag of around 2-3 months. It is worth noting that despite using a "low top" model (i.e., with a model lid at $10 \mathrm{hPa}$ and relatively poor vertical resolution in the stratosphere) in this study, the results are broadly consistent with those from "high top" models (Kim et al. 2014; Sun et al. 2015). There is some suggestion of a similar signal in response to sea ice loss in the BeaufortChukchi Seas, but this is not statistically significant. In the Greenland Sea experiment, there is a significant decrease in $\mathrm{PCH}$ in the lower stratosphere in September, followed by a significant negative tropospheric response in October (Fig. 9e). In the other experiments, the $\mathrm{PCH}$ responses are not significant. Figure 9 suggests that the negative NAO response in response to sea ice loss in the Barents-Kara Seas involves a stratospheric pathway, whereas the wave train responses to sea ice loss in other regions (e.g., the Sea of Okhotsk) are primarily governed by tropospheric processes. Furthermore, the absence of NAONAM responses in the other experiments may reflect the inability of sea ice loss in these regions to trigger a significant stratospheric response. Sun et al. (2015) found that sea ice loss in the Atlantic sector weakened the stratospheric polar vortex, whereas sea ice loss in the Pacific sector strengthened the polar vortex. The results here suggest the Barents-Kara Seas region is especially important in the response to Atlantic sector sea ice loss.

A logical next question to ask is: Why is sea ice loss in the Barents-Kara Seas unique in driving a weakened stratospheric polar vortex? Previous work has suggested that sea ice loss in the Barents-Kara Seas enhances vertical wave activity propagation into the stratosphere, where wave breaking decelerates the stratospheric westerly winds (Kim et al. 2014). Furthermore, it has been proposed that such enhancement of vertical wave activity primarily arises due to an amplification of the zonal wavenumber 1 component (Kim et al. 2014). The concept of linear interference-how the forced response interacts with the climatological stationary waves-appears as a powerful paradigm to explain the effect of extratropical surface forcing (such as Arctic sea ice loss) on vertical wave activity (Garfinkel et al. 2010; Smith et al. 2010; Smith and Kushner 2012). If the forced response projects onto the climatological wave pattern, termed constructive interference, then there is an enhancement of vertical wave activity propagation. Conversely, if the forced response opposes the climatological wave pattern, termed destructive interference, then vertical wave activity propagation is suppressed. Figure 10 suggests that the concept of linear interference can help explain the weakened stratospheric vortex in response to sea ice loss in the Barents-Kara Seas and the absence of such a response in the other experiments. In the case of sea ice loss in the Barents-Kara Seas, the forced response of the zonal wave 1 component (here considering JanuaryFebruary, the month immediately prior to and month of onset of significant positive $\mathrm{PCH}$; see Fig. 9a) interferes constructively with the climatological wave 1 (Fig. 10a). 
a) Barents-Kara Sea

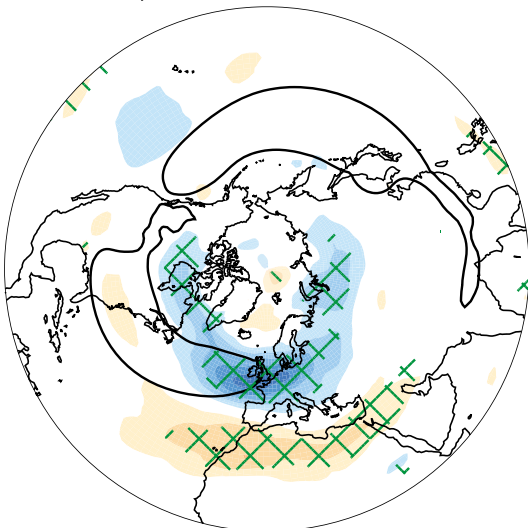

d) Archipelago-Baffin Bay

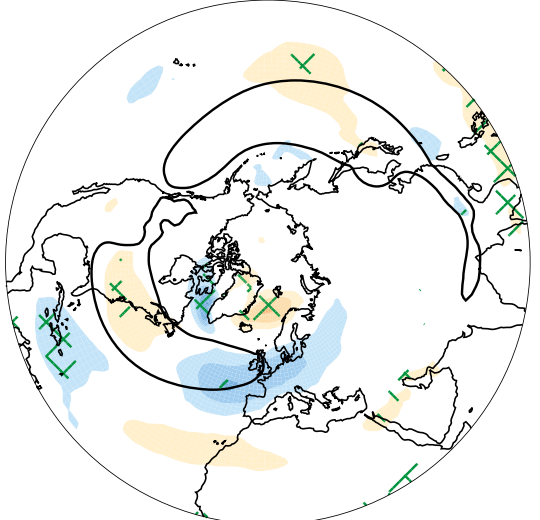

g) Bering Sea

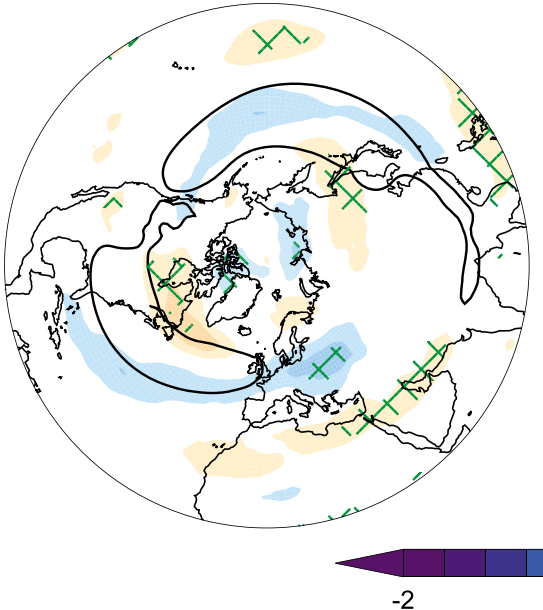

b) East Siberian-Laptev Sea

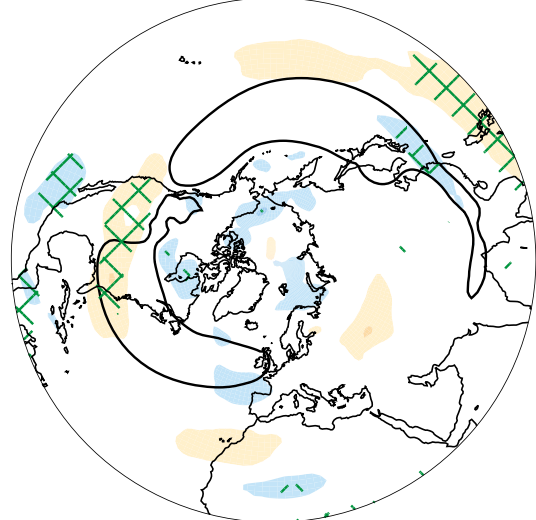

e) Greenland Sea

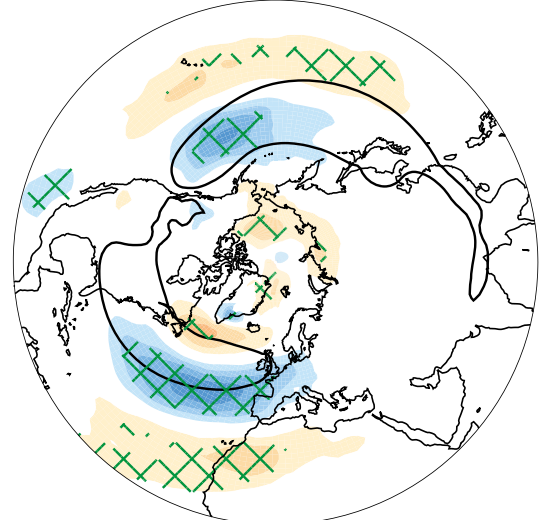

h) Hudson Bay

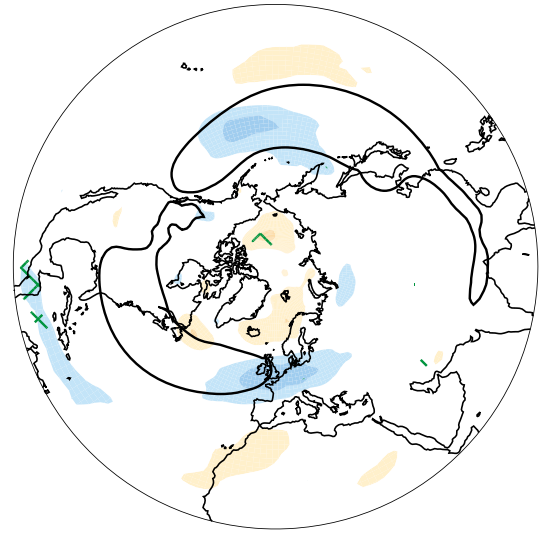

$700 \mathrm{hPa}$ zonal wind $(\mathrm{m} / \mathrm{s})$

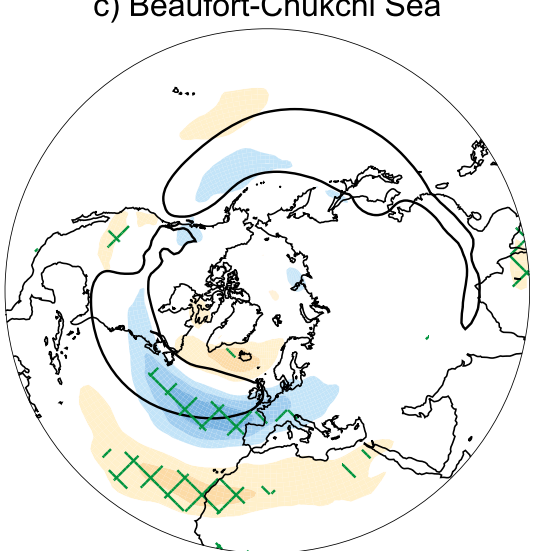

f) Sea of Okhotsk

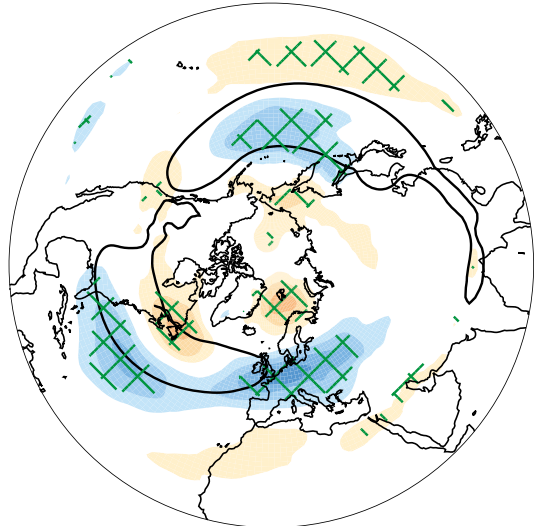

i) Labrador Sea

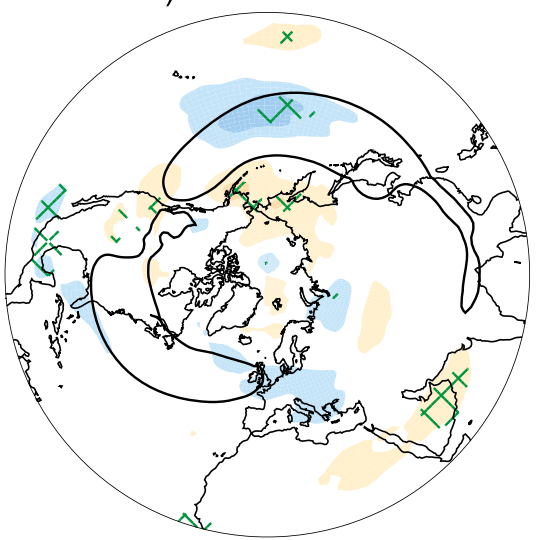

FIG. 7. As in Fig. 3, but for the U700 response. The black contours show the $10 \mathrm{~m} \mathrm{~s}^{-1}$ isolines in the control simulation.

The forced response also displays a characteristic westward tilt with altitude, which is a further indication of vertical wave propagation (Charney and Drazin 1961). The forced response to sea ice loss in the BeaufortChukchi Seas also interferes constructively with the climatological wave, which may help explain the positive (but insignificant) stratospheric $\mathrm{PCH}$ height response in this experiment. In the other experiments, the forced response is either out of phase with the climatological wave 1 (e.g., Figs. 10b,g) or interferes destructively (e.g., Fig. 10h). Furthermore, in some cases the tropospheric and stratospheric responses appear decoupled (e.g., Figs. 10d,f). 
a) Barents-Kara Sea

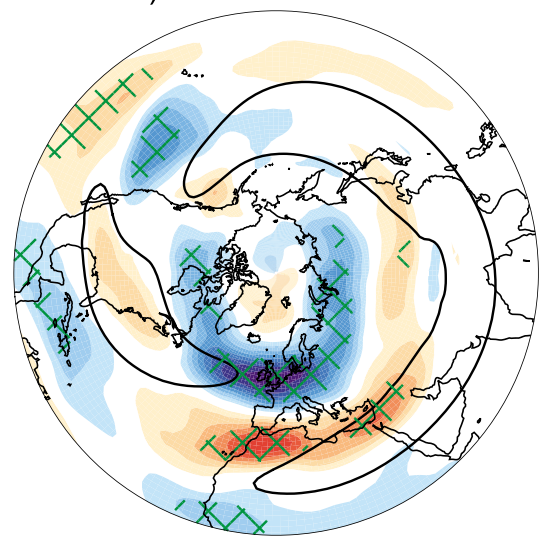

d) Archipelago-Baffin Bay

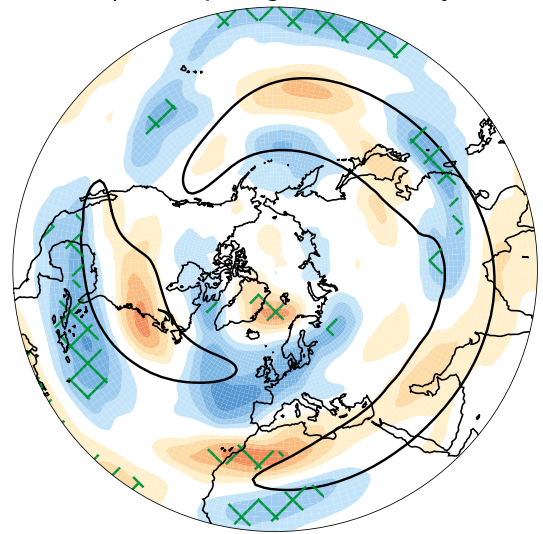

g) Bering Sea

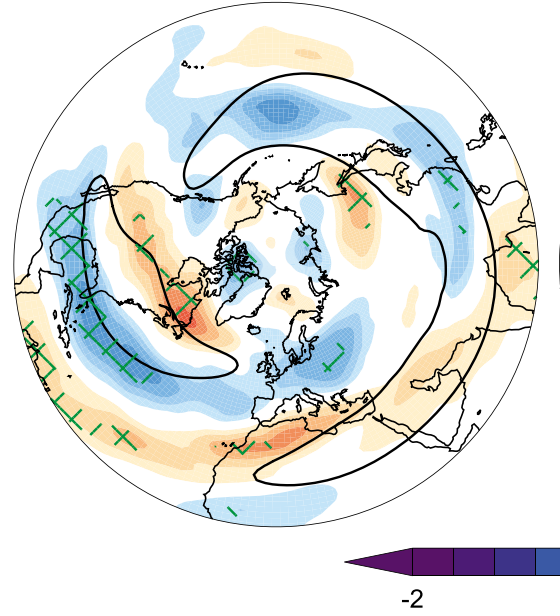

b) East Siberian-Laptev Sea

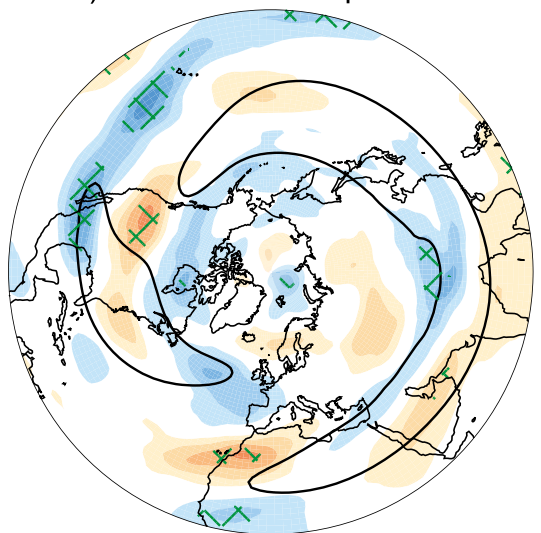

e) Greenland Sea

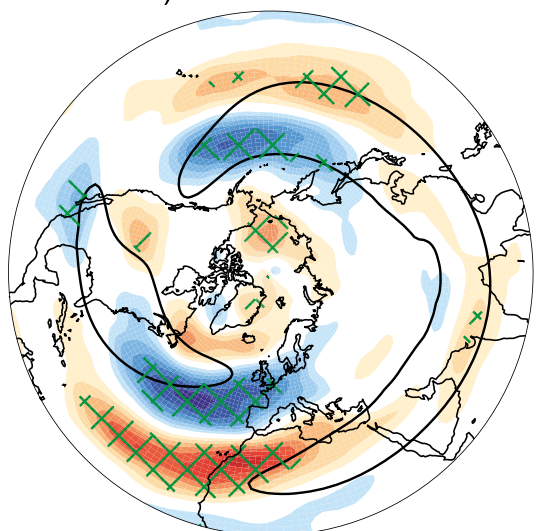

h) Hudson Bay

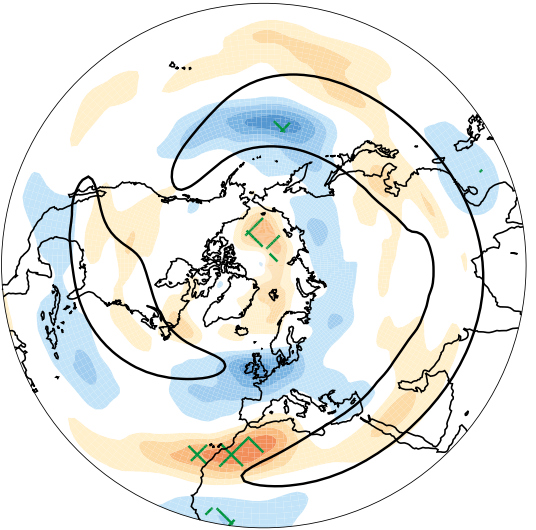

$\begin{array}{llll}-1 & 0 & & \\ & 300 \mathrm{hPa} \text { zonal wind }(\mathrm{m} / \mathrm{s}) & 1\end{array}$ c) Beaufort-Chukchi Sea

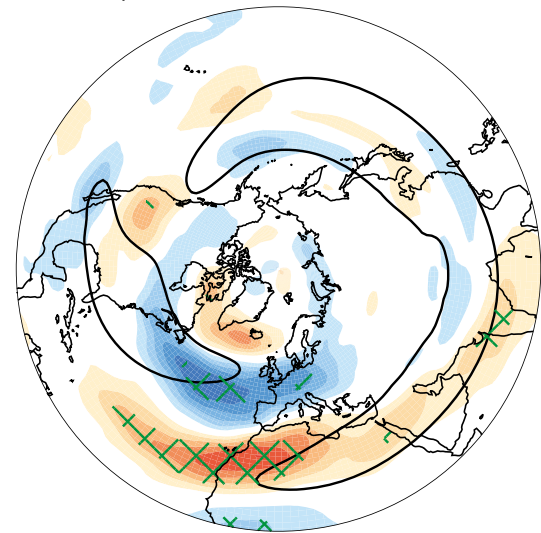

f) Sea of Okhotsk

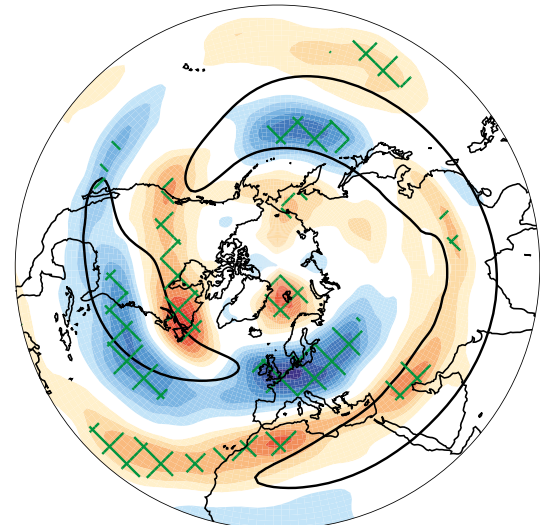

i) Labrador Sea

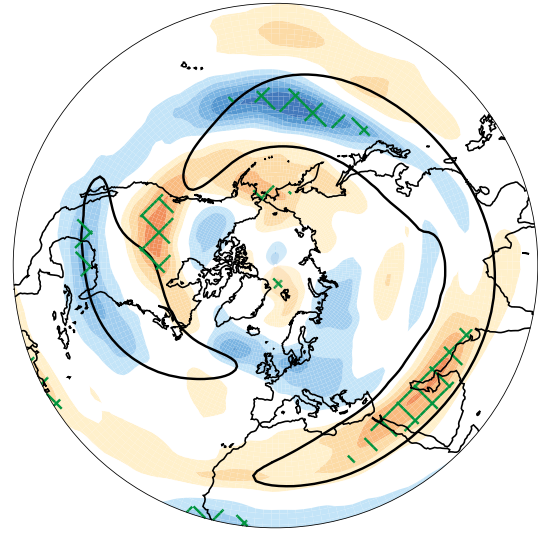

FIG. 8. As in Fig. 3, but for the U300 response. The black contours show the $25 \mathrm{~m} \mathrm{~s}^{-1}$ isolines in the control simulation.

\section{Discussion}

\section{a. Nonlinearity}

An interesting question is to what extent the response to pan-Arctic sea ice loss can be described by a linear combination of the responses to regional sea ice losses.
To assess this, we make use of an 80-member ensemble of simulations prescribed with the same magnitude sea ice forcing as the regional experiments but applied in all regions simultaneously. Figure 11 shows the net heat flux response estimated by summing all the individual responses to regional anomalies (termed the net 
a) Barents-Kara Sea
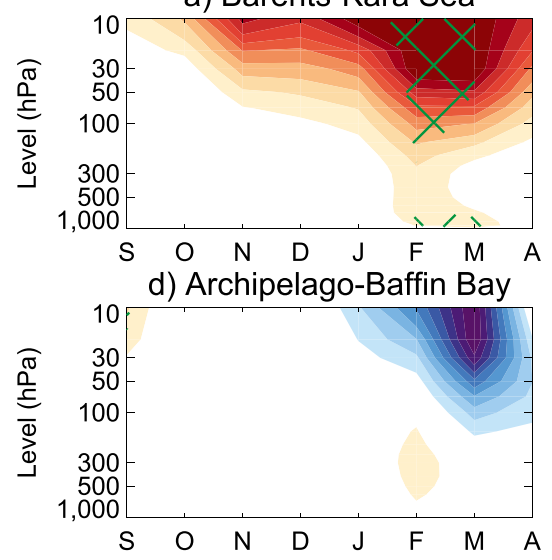

g) Bering Sea

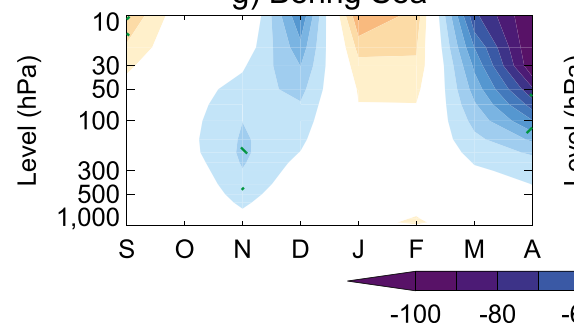

b) East Siberian-Laptev Sea

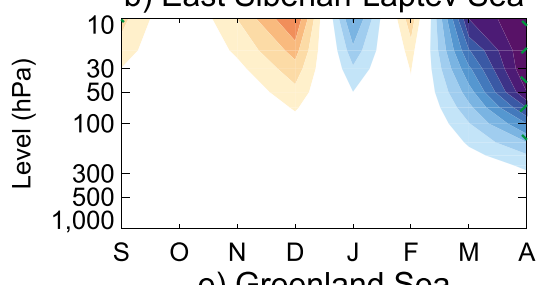

e) Greenland Sea

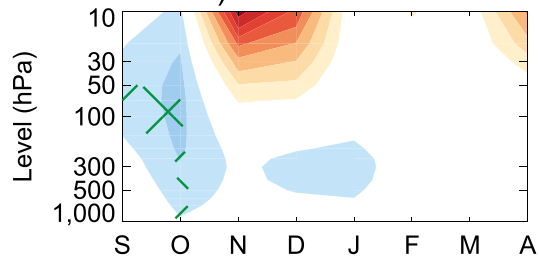

h) Hudson Bay

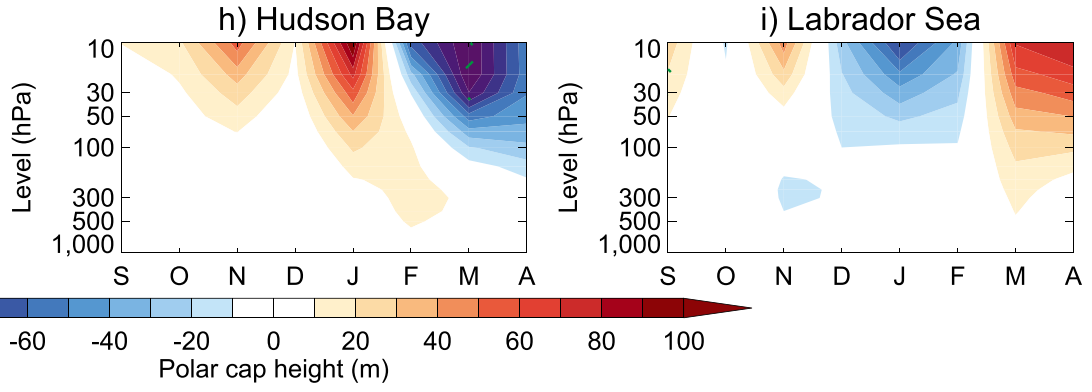

c) Beaufort-Chukchi Sea
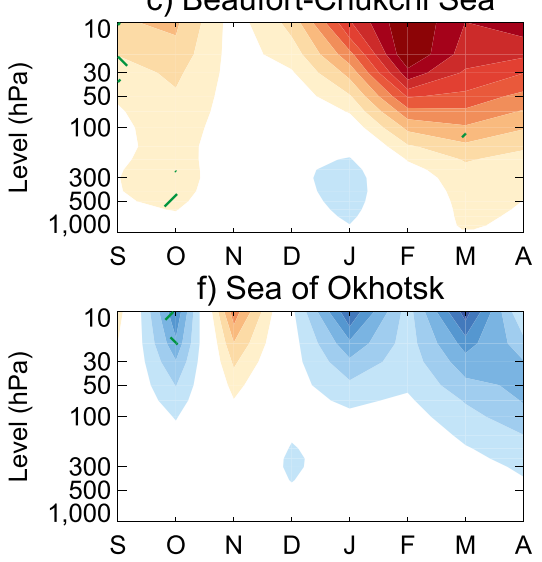

i) Labrador Sea

FIG. 9. Vertical profile of the monthly mean [(left-right) September-April] polar cap (north of $65^{\circ} \mathrm{N}$ )-averaged geopotential height response to sea ice loss in the (a) Barents-Kara Seas, (b) East Siberian-Laptev Seas, (c) Beaufort-Chukchi Seas, (d) Canadian Archipelago-Baffin Bay, (e) Greenland Sea, (f) Sea of Okhotsk, (g) Bering Sea, (h) Hudson Bay, and (i) Labrador Sea. Green hatching denotes a statistically significant response at the $95 \%$ confidence level.

regional response), alongside the response to pan-Arctic sea ice loss (pan-Arctic response). By construction the sea ice area loss is almost identical between the panArctic simulation and the sum of the regional simulations (Fig. 11a). The very slightly larger sea ice area losses in the pan-Arctic experiment compared to the sum of the regional experiments arise due to the smoothing at the edge of the regional domains in the latter (see section 2a). The heat flux changes (and hence, direct thermal forcing of the atmosphere) is highly similar comparing the pan-Arctic and net regional responses (Figs. 11b,c). The main difference is that the pan-Arctic experiment has smaller surface heat flux changes during the period November-January (but especially in November) compared to the sum of the regional responses.

The local (i.e., in regions of sea ice loss) TAS response to pan-Arctic sea ice loss (Fig. 12e) is well approximated by the net regional response (Fig. 12a). However, the remote TAS responses differ considerably. In the pan-Arctic response, warming extends farther south over the continents, whereas the net regional response shows very little continental warming. Instead, the net regional response shows pronounced cooling over Eurasia and North America, which is almost completely absent in the pan-Arctic response. The pan-Arctic and net regional Z500 responses differ markedly. The pan-Arctic response is characterized by elevated Z500 over high latitudes and decreased Z500 over the North Atlantic and North Pacific (Fig. 12f), reminiscent of the negative phase of the NAM. There is a circumpolar weakening of U700 and U300 on the poleward flank of their climatological maximum and a strengthening of U700 and U300 on the equatorward flank in the Atlantic and Pacific sectors (Figs. 12g,h). These features of the pan-Arctic response are highly consistent with the response to projected sea ice loss (Deser et al. 2010, 2015, 2016). In contrast, the net regional response of Z500 (Fig. 12b), U700 (Fig. 12c), and U300 (Fig. 12d) lack this zonally symmetric structure. Thus, it appears that while the local thermodynamical response can be considered a linear combination of the responses to regional sea ice loss, this does not apply for the large-scale atmospheric circulation response and its remote impacts, which are highly nonlinear. It has been previously proposed that the responses to Atlantic sector and Pacific sector sea ice loss may offset each other, leading to a weak response to pan-Arctic 
a) Barents-Kara Sea

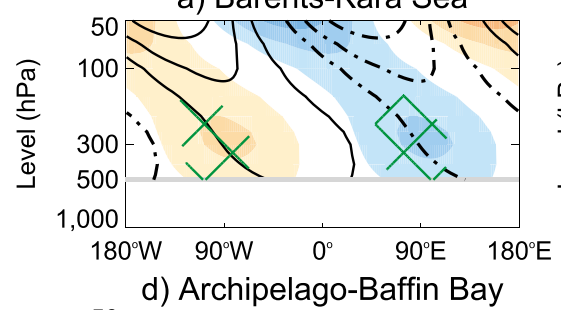

b) East Siberian-Laptev Sea

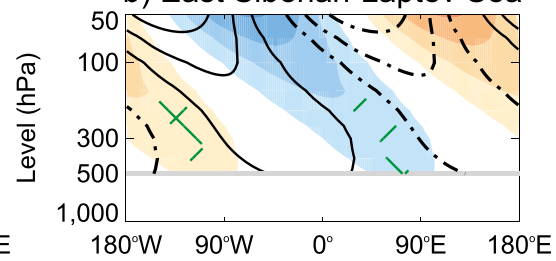

e) Greenland Sea

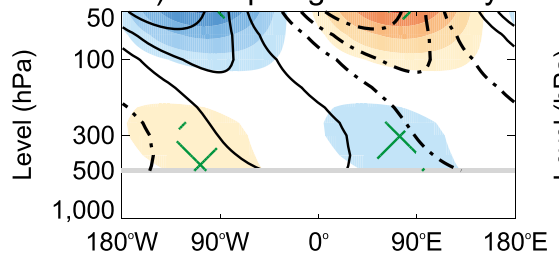

g) Bering Sea
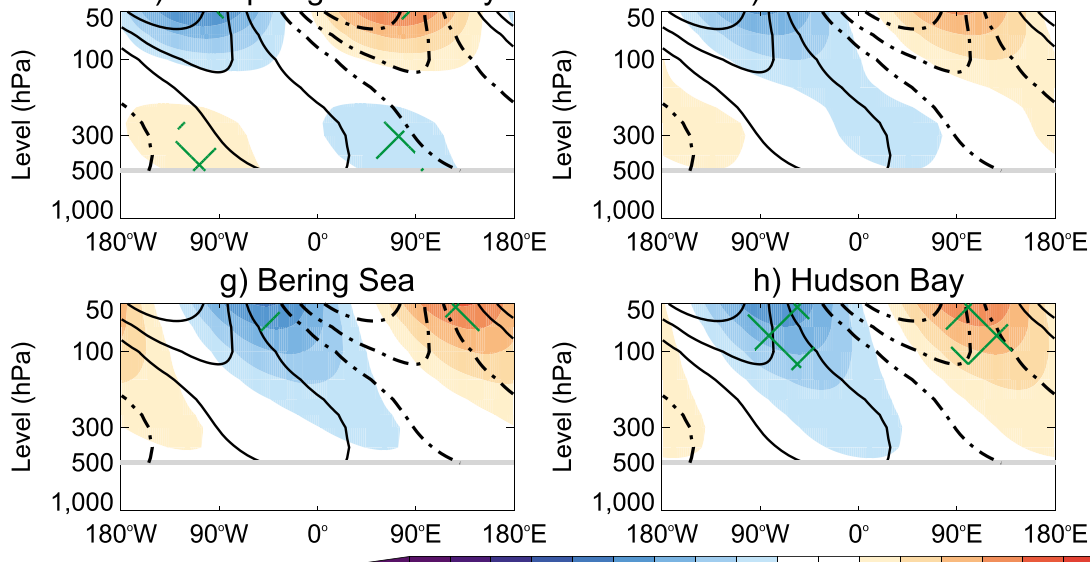

h) Hudson Bay

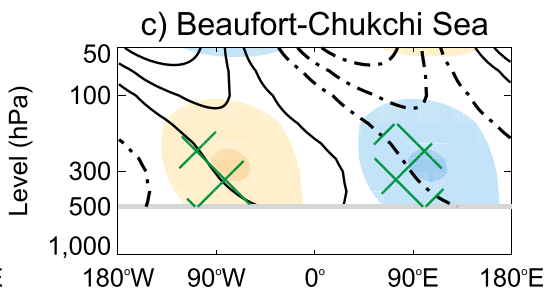

f) Sea of Okhotsk

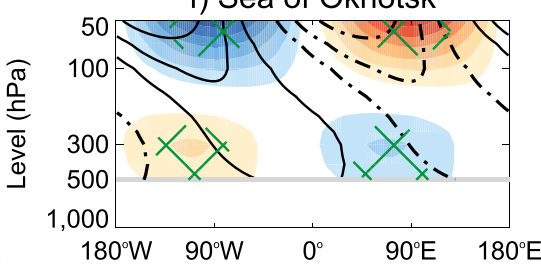

i) Labrador Sea
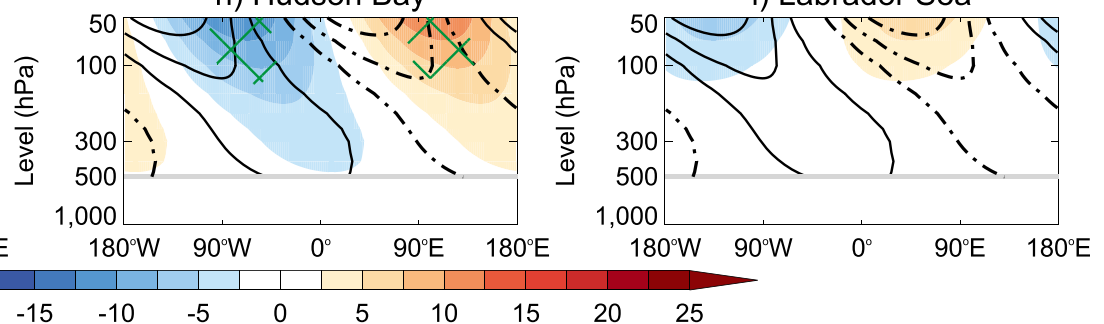

FIG. 10. Vertical cross section of the zonal wavenumber 1 component of the January-February $30^{\circ}-65^{\circ} \mathrm{N}$ mean geopotential height response to sea ice loss in the (a) Barents-Kara Seas, (b) East Siberian-Laptev Seas, (c) Beaufort-Chukchi Seas, (d) Canadian Archipelago-Baffin Bay, (e) Greenland Sea, (f) Sea of Okhotsk, (g) Bering Sea, (h) Hudson Bay, and (i) Labrador Sea. Green hatching denotes a statistically significant response at the $95 \%$ confidence level. Black contours show the climatological wavenumber 1 component in the control simulation and are drawn at intervals of $50 \mathrm{~m}$ (solid for positive; dashed for negative). Pressure levels below $500 \mathrm{hPa}$ are masked due to their intersection with elevated topography.

sea ice loss (Sun et al. 2015). Such an explanation is, however, inadequate to explain the differences shown here between the net regional response and the panArctic response. If it were a simple case of the regional responses offsetting each other (in a linear way), then the net regional response would still be expected to match the pan-Arctic response. That this clearly is not the case suggests nonlinear interaction between the responses to regional sea ice losses.

It would seem reasonable to think of the response to pan-Arctic sea ice loss as being indicative of the effects of the multidecadal trend in sea ice (on these time scales, sea ice is expected to decline in all regions) and the responses to regional anomalies being indicative of the effects of shorter time-scale sea ice variability (on these time scales, sea ice anomalies vary considerably by region). Viewed in this way, the impacts of sea ice anomalies in any given year may be fundamentally different from those expected due to the longer-term decline. For example, while the long-term reduction in sea ice appears to decrease the chances of midlatitude cold winters (Fig. 12e), regional anomalies in any given year may increase the probability of such events (Fig. 3). Equally, while the long-term decline in sea ice appears to favor the negative phase of the NAM (Fig. 12f), regional anomalies appear to have little effect on this dominant mode of variability, with the exception of the Barents-Kara Seas (Fig. 6a).

The possible influence of Arctic sea ice loss on midlatitude cold winters has received a lot of attention (e.g., Honda et al. 2009; Mori et al. 2014; Screen et al. 2015a,b; Ayarzagüena and Screen 2016); thus, it is worthwhile reflecting further on the contrast revealed here between the temperature response to regional and pan-Arctic sea ice loss. One interpretation is that dynamical changes play a leading role in the responses to regional sea ice loss, but thermodynamical warming in the response to pan-Arctic sea ice loss swamps any dynamical cooling. Where cooling is simulated in the regional experiments, it can largely be understood as a response to dynamical (circulation) changes. For example, the net cooling over Europe (Fig. 12a) is associated with easterly wind anomalies (Fig. 12c), which enhance cold-air advection from the Eurasian continental interior. Net cooling over 


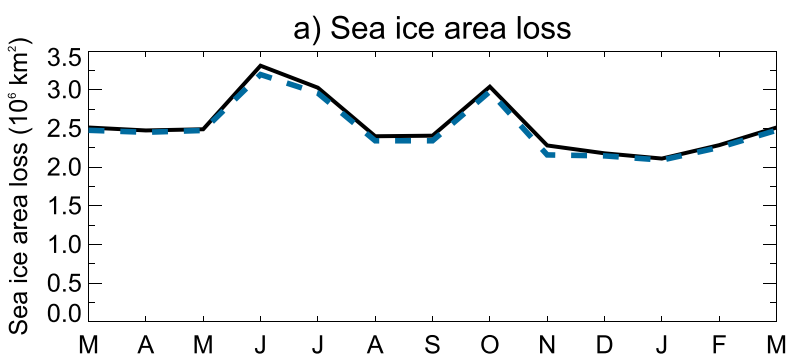

b) Area-average heat flux to atmosphere

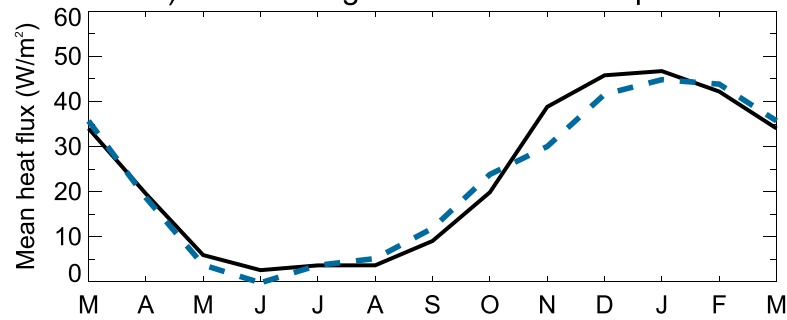

C) Total forcing to atmosphere

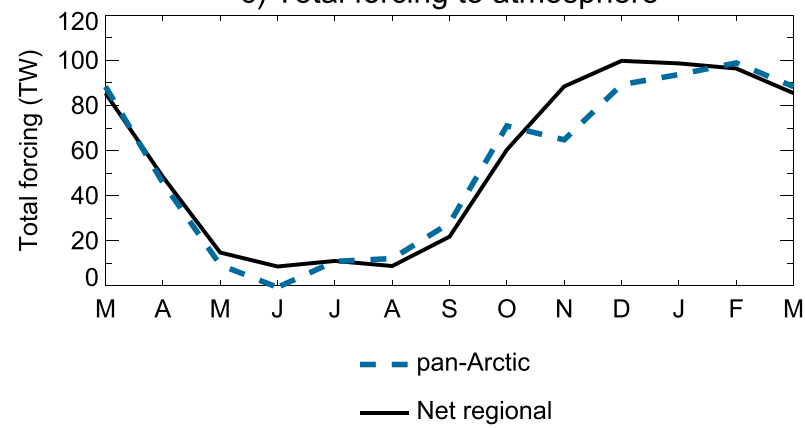

FIG. 11. As in Fig. 2, but comparing the net regional response and the pan-Arctic response.

North America (Fig. 12a) may be linked to an anomalous trough (Fig. 12b) drawing cold Arctic air into midlatitudes. While regional sea ice loss appears capable of inducing areas of dynamical cooling, the warming simulated in response to pan-Arctic sea ice loss is understood to be primarily a thermodynamical response, associated with southward advection of warmed polar air masses (Deser et al. 2010; Screen et al. 2015a,b). There likely exists a delicate interplay between dynamical and thermodynamical influences, as also proposed by Peings and Magnusdottir (2014) in the context of near-term (dynamical cooling) and farterm (thermodynamical warming) midlatitude winter temperature responses to projected (pan-Arctic) sea ice loss.

\section{b. Hot spots}

As part of the ongoing scientific debate on the global effects of Arctic sea ice loss, there has been discussion of possible hot spots of ice-atmosphere interaction: regions where sea ice anomalies are more effective at triggering a large-scale atmospheric response. As a simple metric of the spatial extent of the response, Table 3 provides the percentage of the Northern Hemisphere extratropical area where a significant response (of either sign and of any magnitude, averaged over OctoberMarch) is identified in each regional experiment. Across a range of variables (chosen to capture the largescale atmospheric circulation), the most spatially extensive effects are found in response to sea ice loss in the Barents-Kara Seas and the Sea of Okhotsk. The extensive response to the former may be partly explained by the large net forcing in this experiment during October-March (Fig. 2c). However, this simple explanation is insufficient to explain the extensive response to sea ice loss in the Sea of Okhotsk, as the net OctoberMarch forcing in this experiment is not appreciably larger than in several of the other experiments. Nor can it explain the more spatially restricted responses to sea ice loss in other regions with comparable net forcing, for example, the Labrador Sea and the Bering Sea. Thus, the geographical location of sea ice loss appears important in determining the spatial scale of the response and not just the magnitude of the sea ice forcing.

Large-scale responses in different seasons are triggered by sea ice loss in different places (Table 4). The largest winter responses are driven by sea ice loss in the Sea of Okhotsk and the Labrador Sea. Springtime responses are largest due to sea ice loss in the BarentsKara Seas and the Beaufort-Chukchi Seas, summertime responses due to sea ice loss in the Beaufort-Chukchi Seas and the Bering Sea, and the largest autumn responses driven by sea ice loss in the East SiberianLaptev Sea and the Beaufort-Chukchi Seas. In short, while the location (and timing) of sea ice loss appears important for the spatial scale of the response, there is no single region where sea ice loss consistently produces larger spatial-scale responses. Instead, the so-called hot spots appear seasonally dependent.

\section{c. Nonstationarity}

The results have implications for the stationarity of the atmosphere response to sea ice loss (i.e., how similar is it through time). The location of sea ice loss is anticipated to change with time as the sea ice edge retreats. For example, winter sea ice loss is projected to be largest in the Barents-Kara Seas in the first half of the twentyfirst century but largest over the central Arctic in the second half of the twenty-first century (see, e.g., Ayarzagüena and Screen 2016). The model results presented here suggest differing atmospheric effects of sea ice loss in different regions and thus nonstationarity of the atmospheric response to sea ice loss. Peings and 
a) Net regional TAS

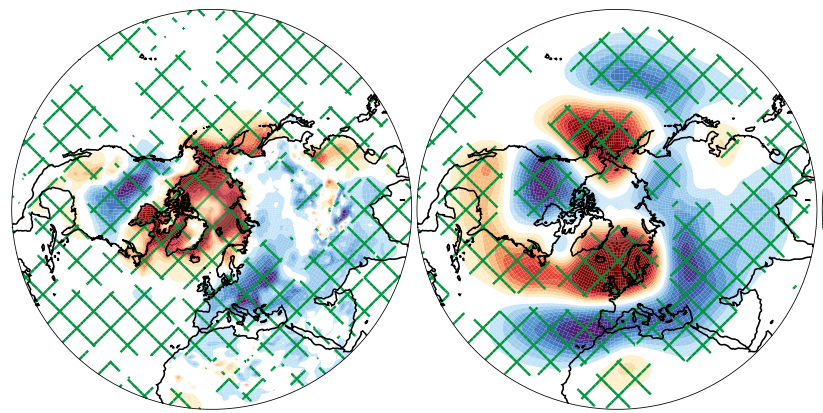

e) Pan-Arctic TAS b) Net regional Z500

f) Pan-Arctic Z500 c) Net regional U700

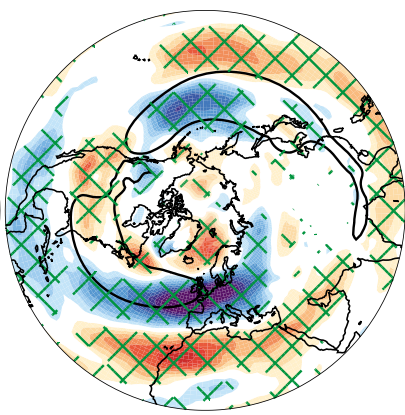

g) Pan-Arctic U700 d) Net regional U300

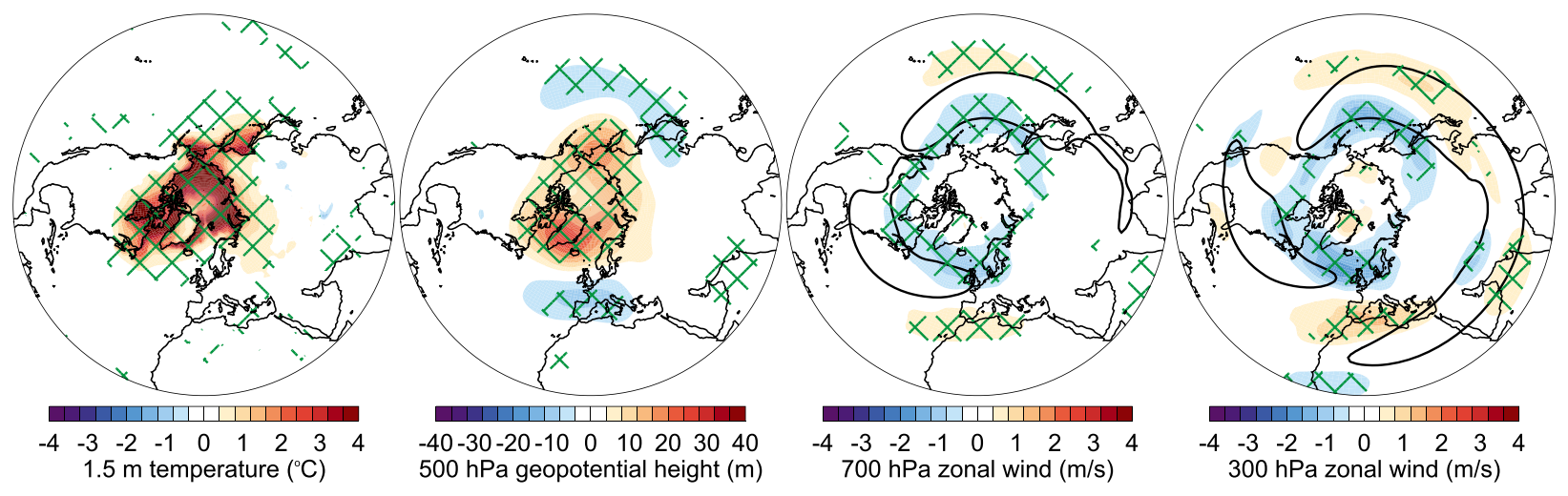

FIG. 12. Net regional response of October-March mean (a) TAS, (b) Z500, (c) U700, and (d) U300. The net regional response is the linear combination of each of the responses to regional sea ice loss [i.e., (a) is the sum of (a)-(i) in Fig. 4]. (e)-(h) As in (a)-(d), but for a simulation prescribed with sea ice loss in all regions simultaneously. Green hatching denotes statistically a significant response at the $95 \%$ confidence level.

Magnusdottir (2014) also noted differing atmospheric responses to present-day and future Arctic sea ice loss, which they related to different spatial patterns of sea ice anomalies. This raises the possibility that the transient response to sea ice loss may be rather different to the equilibrium response. Most previous studies examining the atmospheric response to projected Arctic sea ice loss have considered the equilibrium response to future sea ice conditions (e.g., Deser et al. 2010, 2015, 2016; Peings and Magnusdottir 2014; Screen et al. 2015a,b; Ayarzagüena and Screen 2016).

\section{d. Atmosphere-ocean coupling}

A potential limitation of the simulations presented in this study is the lack of atmosphere-ocean coupling. In this context it is worth briefly discussing the results of Deser et al. (2016). Deser et al. performed an analogous sea ice loss experiment in an atmosphere-only framework and with the atmospheric model coupled to a fulldepth dynamical ocean model. These authors found that while the tropical responses to Arctic sea ice loss were fundamentally different between the uncoupled and coupled cases, the Northern Hemisphere extratropical responses were broadly consistent in the spatial pattern but slightly damped in magnitude in the uncoupled case versus the coupled case. For this reason, the present study has restricted attention to the Northern Hemisphere extratropics. While the results of Deser et al. suggest that the lack of ocean coupling in the presented experiments may lead to a muted response, there is no

TABLE 3. Percentage of the Northern Hemisphere extratropical $\left(30^{\circ}-90^{\circ} \mathrm{N}\right)$ area over which significant October-March mean responses are identified.

\begin{tabular}{lccccccccc}
\hline \hline & B-K & ES-L & B-C & Ar-B & Gre & Okh & Ber & Hud & Lab \\
\hline Z500 & 18.8 & 0.8 & 1.8 & 3.9 & 9.4 & 25.2 & 5.4 & 0.4 & 5.9 \\
U700 & 14.9 & 4.4 & 4.0 & 4.2 & 11.2 & 17.3 & 6.6 & 0.8 & 3.4 \\
U300 & 15.9 & 2.6 & 2.8 & 2.3 & 11.5 & 19.0 & 5.7 & 1.9 & 5.3 \\
\hline
\end{tabular}


TABLE 4. Percentage of the Northern Hemisphere extratropical $\left(30^{\circ}-90^{\circ} \mathrm{N}\right)$ area over which significant seasonal mean Z500 responses are identified.

\begin{tabular}{lrrrrrrrrr}
\hline \hline & B-K & ES-L & B-C & Ar-B & Gre & Okh & Ber & Hud & Lab \\
\hline DJF & 12.3 & 3.6 & 3.6 & 5.9 & 5.80 & 28.8 & 7.3 & 5.7 & 15.3 \\
MAM & 14.9 & 5.7 & 13.7 & 0.3 & 10.1 & 7.3 & 8.7 & 2.0 & 3.8 \\
JJA & 6.9 & 7.0 & 15.3 & 5.0 & 13.8 & 2.6 & 17.7 & 6.8 & 9.9 \\
SON & 6.1 & 7.1 & 8.2 & 6.2 & 6.9 & 5.5 & 6.8 & 1.0 & 4.1 \\
\hline
\end{tabular}

reason to believe that the main conclusions would be fundamentally different if a coupled model framework has been used. That said, further work with coupled models would be valuable and is planned.

\section{Conclusions}

On the basis of atmospheric model simulations with prescribed sea ice loss in nine distinct geographical regions it is concluded that:

- The atmosphere responds very differently to sea ice loss in different geographical regions. In some regions, sea ice loss triggers large-scale dynamical responses, whereas in other regions sea ice loss induces only local thermodynamical changes.

- For October-March, the largest spatial-scale responses are driven by sea ice loss in the BarentsKara Seas and the Sea of Okhotsk; however, different regions of sea ice loss assume greater importance in other seasons.

- The atmosphere responds very differently to regional sea ice losses than to pan-Arctic sea ice loss. For example, regional ice losses cause predominantly cooling over the high- and midlatitude continents, whereas pan-Arctic sea ice loss causes warming.

- The cumulative effects of regional sea ice losses are nonlinear (nonadditive), implying sea ice loss in one region affects the response to sea ice loss in another region.

- The atmospheric response to sea ice loss is likely nonstationary, and will vary in time and space depending on the geographical regions of sea ice losses.

- Diversity in previously published simulated responses to sea ice loss can be partly explained by the different spatial patterns of sea ice loss imposed.

Acknowledgments. Thanks to Blanca Ayarzagüena for calculating the CAO statistics, and to three anonymous reviewers for their time and feedback. HadISST data were obtained from the Met Office Hadley Centre website (http://www.metoffice.gov.uk/hadobs/hadisst). Model simulations were performed on the ARCHER
U.K. National Supercomputing Service. Data from these experiments are available from the author upon reasonable request. This work was supported by Natural Environment Research Council Grants NE/J019585/1 and NE/M006123/1.

\section{REFERENCES}

Ayarzagüena, B., and J. A. Screen, 2016: Future Arctic sea-ice loss reduced severity of cold air outbreaks in midlatitudes. Geophys. Res. Lett., 43, 2801-2809, doi:10.1002/2016GL068092.

Barnes, E. A., and J. A. Screen, 2015: The impact of Arctic warming on the midlatitude jet-stream: Can it? Has it? Will it? Wiley Interdiscip. Rev.: Climate Change, 6, 277-286, doi:10.1002/wcc.337.

Bhatt, U. S., and Coauthors, 2014: Implications of Arctic sea ice decline for the Earth system. Annu. Rev. Environ. Resour., 39, 57-89, doi:10.1146/annurev-environ-122012-094357.

Blackport, R., and P. J. Kushner, 2016: The transient and equilibrium climate response to rapid summertime sea ice loss in CCSM4. J. Climate, 29, 401-417, doi:10.1175/ JCLI-D-15-0284.1.

Charney, J. G., and P. G. Drazin, 1961: Propagation of planetaryscale disturbances from the lower into the upper atmosphere. J. Geophys. Res., 66, 83-109, doi:10.1029/JZ066i001p00083.

Cohen, J., and Coauthors, 2014: Recent Arctic amplification and extreme mid-latitude weather. Nat. Geosci., 7, 627-637, doi:10.1038/ngeo2234.

Cvijanovic, I., and K. Caldeira, 2015: Atmospheric impacts of sea ice decline in $\mathrm{CO}_{2}$ induced global warming. Climate Dyn., 44, 1173-1186, doi:10.1007/s00382-015-2489-1.

Deser, C., G. Magnusdottir, R. Saravanan, and A. Phillips, 2004: The effects of North Atlantic SST and sea ice anomalies on the winter circulation in CCM3. Part II: Direct and indirect components of the response. J. Climate, 17, 877-889, doi:10.1175/1520-0442(2004)017<0877:TEONAS >2.0.CO;2.

$\longrightarrow$, R. A. Tomas, M. A. Alexander, and D. Lawrence, 2010: The seasonal atmospheric response to projected Arctic sea ice loss in the late twenty-first century. J. Climate, 23, 333-351, doi:10.1175/2009JCLI3053.1.

,$- \ldots$, and L. Sun, 2015: The role of ocean-atmosphere coupling in the zonal-mean atmospheric response to Arctic sea ice loss. J. Climate, 28, 2168-2186, doi:10.1175/JCLI-D-14-00325.1.

$\longrightarrow$, L. Sun, R. A. Tomas, and J. A. Screen, 2016: Does ocean coupling matter for the northern extratropical response to projected Arctic sea ice loss? Geophys. Res. Lett., 43, 21492157, doi:10.1002/2016GL067792.

Garfinkel, C. I., D. L. Hartmann, and F. Sassi, 2010: Tropospheric precursors of anomalous Northern Hemisphere stratospheric polar vortices. J. Climate, 23, 3282-3299, doi:10.1175/2010JCLI3010.1. 
Honda, M., K. Yamazaki, Y. Tachibana, and K. Takeuchi, 1996: Influence of Okhotsk sea-ice extent on atmospheric circulation. Geophys. Res. Lett., 23, 3595-3598, doi:10.1029/ 96GL03474.

_- J. Inoue, and S. Yamane, 2009: Influence of low Arctic sea ice minima on anomalously cold Eurasian winters. Geophys. Res. Lett., 36, L08707, doi:10.1029/2008GL037079.

IPCC, 2013: Climate Change 2013: The Physical Science Basis. Cambridge University Press, 1535 pp., doi:10.1017/CBO9781107415324.

Kim, B.-M., S.-W. Woo, S.-K. Min, J.-H. Jeong, S.-J. Kim, X. Zhang, T. Shim, and J.-H. Yoon, 2014: Weakening of the stratospheric polar vortex by Arctic sea-ice loss. Nat. Commun., 5, 4646, doi:10.1038/ncomms5646.

Kinnard, C., C. M. Zdanowicz, D. A. Fisher, E. Isaksson, A. de Vernal, and L. G. Thompson, 2011: Reconstructed changes in Arctic sea ice over the past 1,450 years. Nature, 479, 509-512, doi:10.1038/nature10581.

Koenigk, T., M. Caian, G. Nikulin, and S. Schimanke, 2016: Regional Arctic sea ice variations as predictor for winter climate conditions. Climate Dyn., 46, 317-337, doi:10.1007/ s00382-015-2586-1.

Magnusdottir, G., C. Deser, and R. Saravanan, 2004: The effects of North Atlantic SST and sea ice anomalies on the winter circulation in CCM3. Part I: Main features and storm track characteristics of the response. J. Climate, 17, 857-876, doi:10.1175/1520-0442(2004)017<0857:TEONAS > 2.0.CO;2.

Martin, G. M., and Coauthors, 2011: The HadGEM2 family of Met Office Unified Model climate configurations. Geosci. Model Dev., 4, 723-757, doi:10.5194/gmd-4-723-2011.

Mori, M., M. Watanabe, H. Shiogama, J. Inoue, and M. Kimoto, 2014: Robust Arctic sea-ice influence on the frequent Eurasian cold winters in past decades. Nat. Geosci., 7, 869-873, doi:10.1038/ngeo2277.

Nakamura, T., K. Yamazaki, K. Iwamoto, M. Honda, Y. Miyoshi, Y. Ogawa, Y. Timikawa, and J. Ukita, 2016: The stratospheric pathway for Arctic impacts on midlatitude climate. Geophys. Res. Lett., 43, 3494-3501, doi:10.1002/2016GL068330.

Overland, J., J. A. Francis, R. Hall, E. Hanna, S.-J. Kim, and T. Vihma, 2015: The melting Arctic and midlatitude weather patterns: Are they connected? J. Climate, 28, 7917-7932, doi:10.1175/JCLI-D-14-00822.1.

Pedersen, R. A., I. Cvijanovic, P. L. Langen, and B. M. Vinther, 2016: The impact of regional arctic sea ice loss on atmospheric circulation and the NAO. J. Climate, 29, 889-902, doi:10.1175/ JCLI-D-15-0315.1.

Peings, Y., and G. Magnusdottir, 2014: Response of the wintertime Northern Hemisphere atmospheric circulation to current and projected Arctic sea ice decline: A numerical study with CAM5. J. Climate, 27, 244-264, doi:10.1175/JCLI-D-13-00272.1.

Petoukhov, V., and V. A. Semenov, 2010: A link between reduced Barents-Kara sea ice and cold winter extremes over northern continents. J. Geophys. Res., 115, D21111, doi:10.1029/ 2009JD013568.

Post, E., and Coauthors, 2013: Ecological consequences of sea-ice decline. Science, 341, 519-524, doi:10.1126/science.1235225.

Rayner, N. A., D. E. Parker, E. B. Horton, C. K. Folland, L. V. Alexander, D. P. Rowell, E. C. Kent, and A. Kaplan, 2003: Global analyses of sea surface temperature, sea ice, and night marine air temperature since the late nineteenth century. J. Geophys. Res., 108, 4407, doi:10.1029/2002JD002670.

Rinke, A., K. Dethloff, W. Dorn, D. Handorf, and J. C. Moore, 2013: Simulated Arctic atmospheric feedbacks associated with late summer sea ice anomalies. J. Geophys. Res. Atmos., 118, 7698-7714, doi:10.1002/jgrd.50584.

Scaife, A., and Coauthors, 2014: Skillful long-range prediction of European and North American winters. Geophys. Res. Lett., 41, 2514-2519, doi:10.1002/2014GL059637.

Screen, J. A., I. Simmonds, C. Deser, and R. Tomas, 2013: The atmospheric response to three decades of observed Arctic sea ice loss. J. Climate, 26, 1230-1248, doi:10.1175/ JCLI-D-12-00063.1.

_ C. Deser, I. Simmonds, and R. Tomas, 2014: Atmospheric impacts of Arctic sea-ice loss, 1979-2009: Separating forced change from atmospheric internal variability. Climate Dyn., 43, 333-344, doi:10.1007/s00382-013-1830-9.

$\longrightarrow,-$, and L. Sun, 2015a: Reduced risk of North American cold extremes due to continued Arctic sea ice loss. Bull. Amer. Meteor. Soc., 96, 1489-1503, doi:10.1175/BAMS-D-14-00185.1.

$\longrightarrow, \ldots$, and — 2015b: Projected changes in regional climate extremes arising from Arctic sea ice loss. Environ. Res. Lett., 10, 084006, doi:10.1088/1748-9326/10/8/084006.

Simmonds, I., 2015: Comparing and contrasting the behavior of Arctic and Antarctic sea ice over the 35 year period 19792013. Ann. Glaciol., 56, 18-28, doi:10.3189/2015AoG69A909.

Smith, K. L., and P. J. Kushner, 2012: Linear interference and the initiation of extratropical stratosphere-troposphere interactions. J. Geophys. Res., 117, D13107, doi:10.1029/ 2012JD017587.

— C. G. Fletcher, and P. J. Kushner, 2010: The role of linear interference in the annular mode response to extratropical surface forcing. J. Climate, 23, 6036-6050, doi:10.1175/ 2010JCLI3606.1.

Sun, L., C. Deser, and R. A. Tomas, 2015: Mechanisms of stratospheric and tropospheric circulation response to projected Arctic sea ice loss. J. Climate, 28, 7824-7845, doi:10.1175/ JCLI-D-15-0169.1.

Vihma, T., 2014: Effects of Arctic sea ice decline on weather and climate: A review. Surv. Geophys., 35, 1175-1214, doi:10.1007/ s10712-014-9284-0.

Walsh, J. E., 2014: Intensified warming of the Arctic: Causes and impacts on middle latitudes. Global Planet. Change, 117, 5263, doi:10.1016/j.gloplacha.2014.03.003. 